مجلة كلية التربية ـ جامعة الإسكندرية المجلد السادس والعشرون (العدد الخامس أ) لسنة 17 ـ ب

\title{
المعبود ذو الثري ودوره في الديانة النبطية
}

د. محمد دسوقي حسن عبد العزيز**

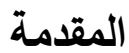

الايانة النبطية

نشـأت مملكـة الأنبـاط ( خريطـة رقـم () شـمال غـرب الجزيـرة

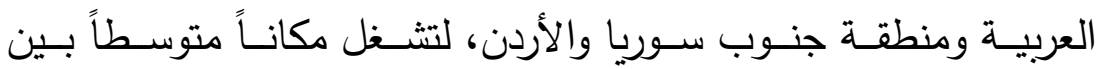

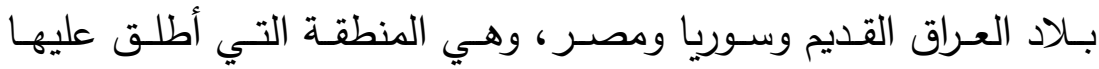

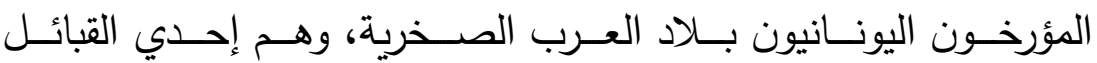

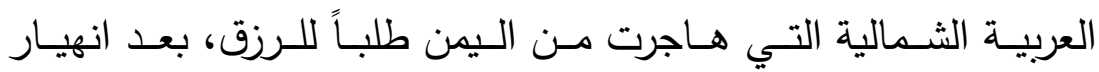

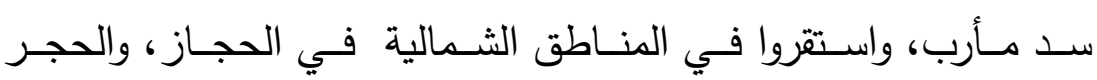

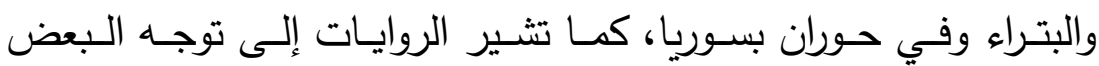

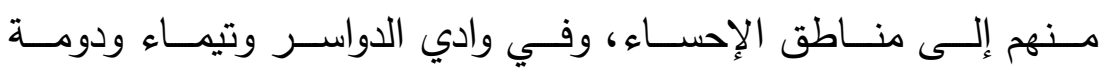

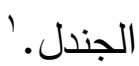

وتقع مملكة الأنباط في ملتقى الطرق التجارية، وقد مكنها هذا الموقع من السيطرة على هذه الطرق، فازدهرت مملكتهم منذ القرن الرابع ق.م،

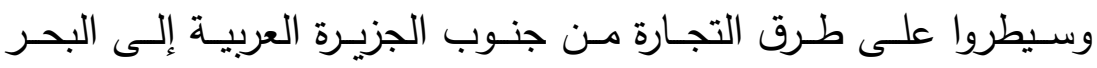

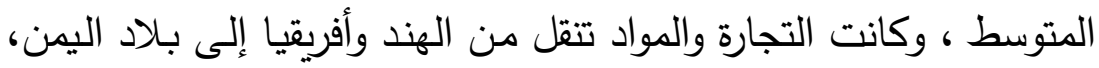

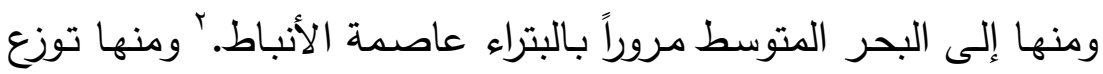

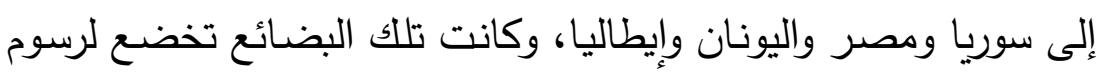

* الأستاذ المساعد بكلية الآداب - قسم التاريخ - جامعة الإسكندرية

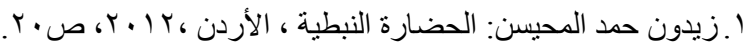

${ }^{2}$ Scott ,A.P " The History Of The Nabataeans " in The Sarcophagus of On ancient Civilization Petra , Edom, and The Edomite's , by George Robinson, Macmillan ,New York ,XV111,1930, p375. 
مالية تدفع للحكومة النبطية، وفي خلال ثلاثة قرون استطاعوا النهوض بمملكتهر ، وتحولوا من حياة البداوة إلى شعب رئ رائد في التجارة والزراعة

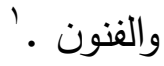

إن ازدهـار مملكـة الأنباط قد جعلهـا تلعب دوراً حاسماً في التجـارة العالمية، وامتدت تجارتهم في جميع مناطق الشرق الأدنى القديم، وكانت القوافل التجارية تمر عبر الحجاز وحتي البتراء ثم غرباً إلى ساحل البحر

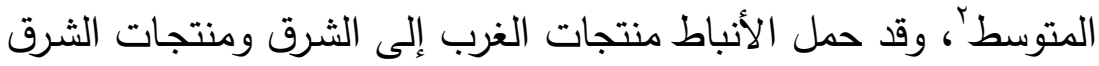
إلى الغرب، وشكلوا همزة وصل تجاريـة بين أقطار العالم القديمّ، ومثلوا

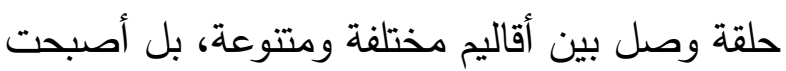
بمثابة جسر يربط أعرق حضارتين من حضارات العالم القديم، وهما

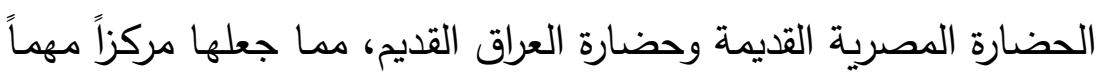
لتجارة الترانزيت بين الدول المهمة في العالم القديم.؛ وجعلها تحتل موقعاً

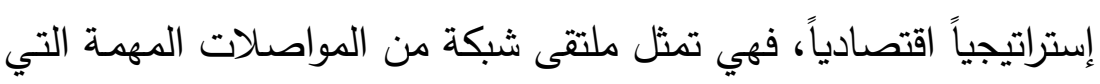

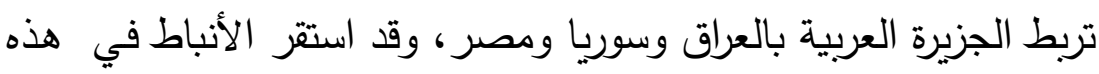

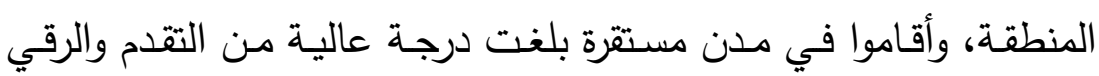

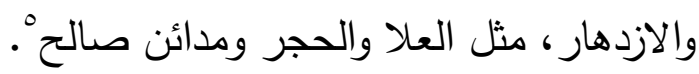

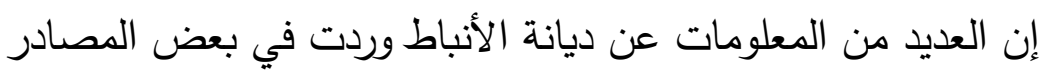

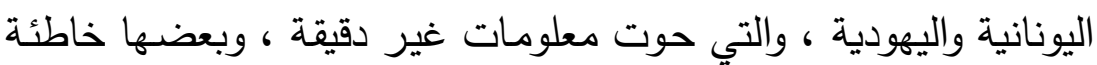

Bedal .A.L "The Petra Pool- Complex, Gorgios Press, New

York,,2003,p9

2 Brill , Leiden ,2001,p3-18."Healey ,J,F" The Religion of The Nabataeans

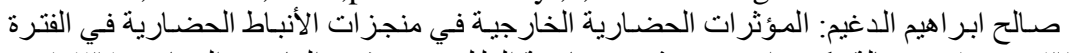

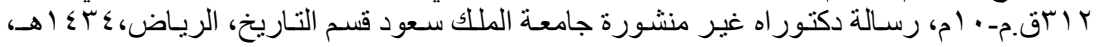
؛ كمـال سليمان الصليبي: الإطـار الخـارجي لجاهليـة العرب، دراسـات في تـاريخ الجزيرة العربيـة،

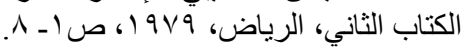
'Julian Bows her," The Frontier Post Of median Saleh" in The Defense of the Roman and By zantine East, Philip Free man, David Kennedy eds, Part 1,oxford, 1986, p23. 
فيما يتعلق بالديانة النبطية، وذلك بسبب عدم معرفتهم بالعادات والتقاليد

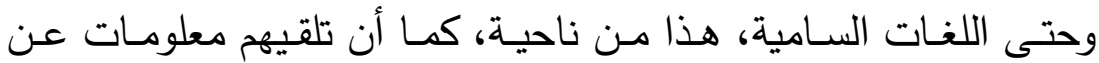

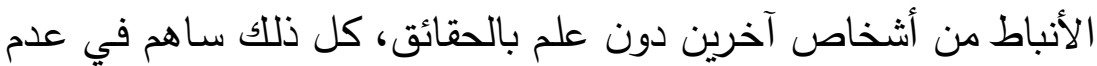

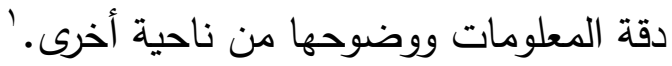

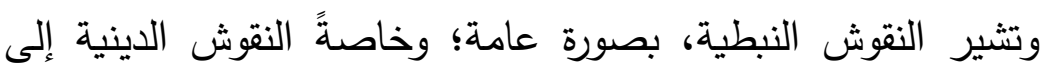

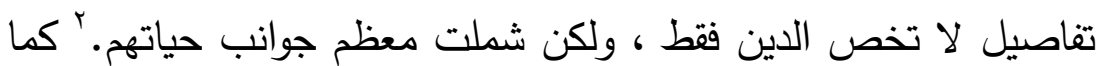
تُعد الآثار والمصادر التاريخية والدينية مثل: الثعر الجاهلي والقرآن

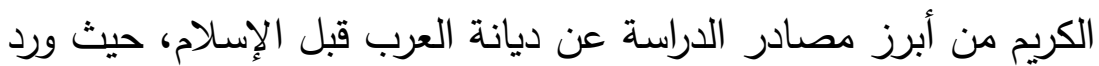

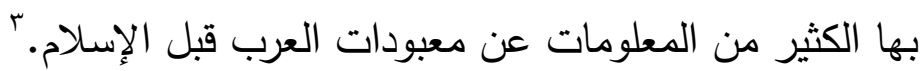
وتُعد المصادر العربية القديمة والتي تحدثت عن آلهة الجزيرة الجيردات العربية وأماكن العبادة فيها من أوثق المصادر وأدقها، وذللك على الرغم من تحاشي المؤرخين العرب في فجر الإسلام، الحديث عن الشعائر الدينية والمعبودات،وكل ما يتعلق بفترة قبل الإسلام.

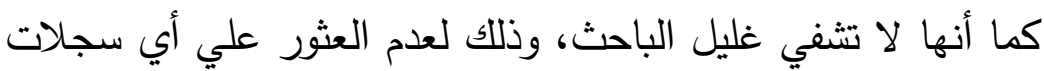

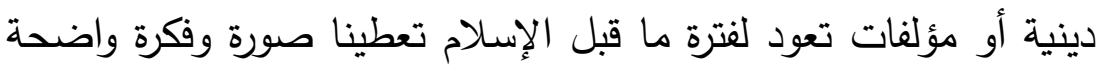
عن الأوضاع الدينية والسياسية والاجتماعية، مما ساعد في عدم إعطاء صورة واضحة عن ديانة العرب قبل الإسلام بشكل يصعب على الباحث معرفة الفكر الديني العربي بكل تفاصيله. وتُعد المصادر الكتابية من أهم وسائل نقل تجارب المجتمعات القعابل القديمة

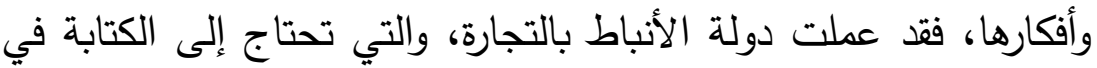

زيدون المحيسن: المرجع السابق، صه؛؛.

2 Healy,J , E ." The Nabataean Tomb Inscriptions of median Salah" oxford, university press oxford, 1993 p40

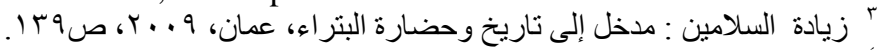

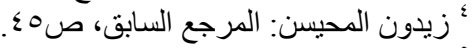

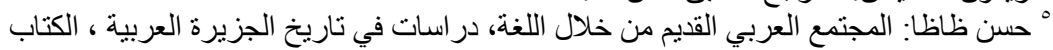

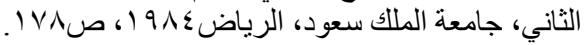


المعاملات التجارية مع الحضارات التي تتعامل معها، وكان الآراميون هم أقرب الشعوب المتحضرة إلي الأنباط ، وقد تأثر الأنباط بالآراميين

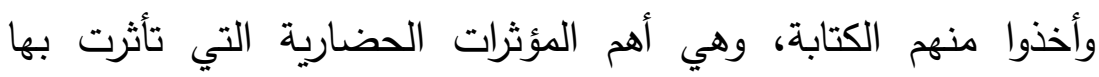
الحضارة النبطية.' حيث كانت لغة المعاملات التجارية في أسواق سوريا

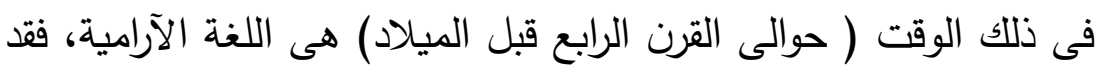
اخذ الأنباط اللغة والخط الآرامى وطوروه إلى الخط النبطي.

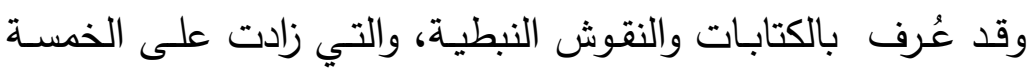

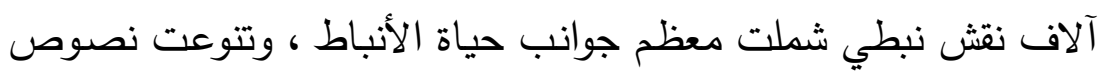

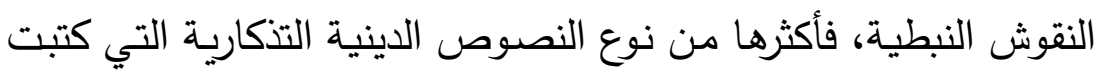

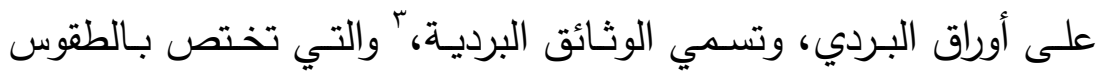

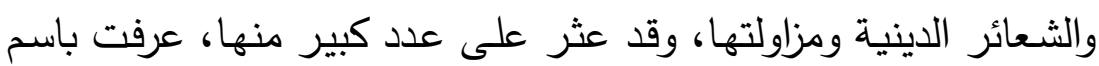

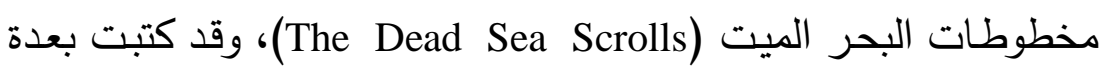
لغات منها : الآرامية والعبرية واليونانية والنبطية.

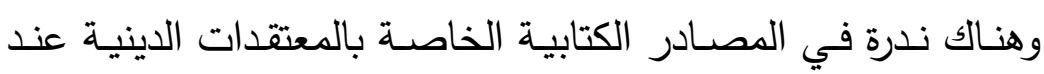
الأنباط ، ولكن يستطيع الباحث أن يتلمس بعض الإشارات التي ترد في

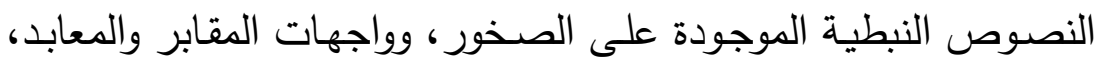

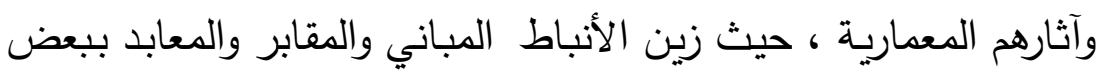
تماثيل المعبودات. ْوعلى عُملتهم، والتي كانت

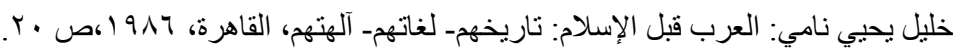

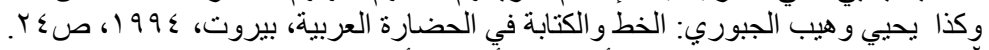

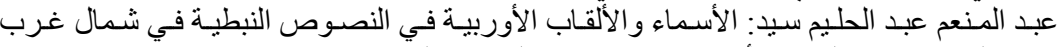

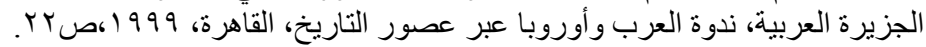

${ }^{3}$ Healy, J,F " Text book of Syrian Semitic Inscription " vol 4 Aramaic Inscriptions and documents of the Roman Period ,oxford university press, $2009, \mathrm{p} 28$.

4 Vanderkom,J,C \& Flint "The meaning of the Dead sea Scrolls: Their Significance for Understanding the Bible ,Judaism ,Jesus, and Christianity, Landan,2002,p3-18.

${ }^{5}$. Healey ,J,F, op ,cit p1. 
مجلة كلية التربية ـ جامعة الإسكندرية المجلد السادس والعشرون (العدد الخامس أ) لسنة 17 ـ ب

تشير إلى بعض الرموز والمعبودات الدينية واقتصرت هذه الإشارات على

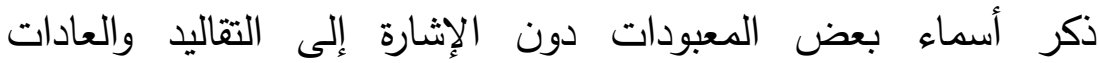
والمعتقدات الدينية.' وقد تم معرفة بعض المعبودات عن طريق تحليل

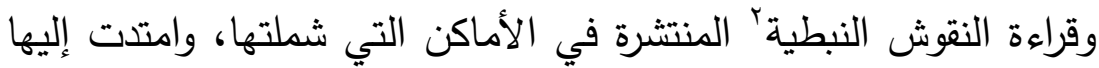
مملكة الأنباط، ووصلت اليها تجارهم من دمشق والرقيم وصحراء النقب جنوب فلسطين شمالاً، وإلي صحراء سيناء والصحراء الشرقية لمصر غرباً، وإلى العلا، وربما الفاو جنوباً، وحوران في الثمال الشرقي.

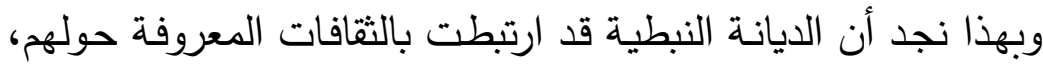
لأن الأنباط عاشوا مثل جيرانهم الساميين الذين جابوا الصحراء ثم مكثوا

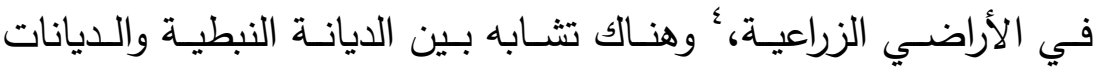

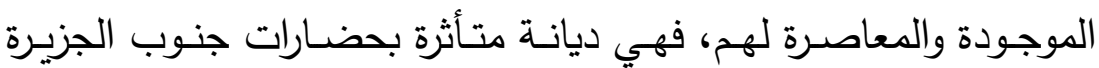
العربية والحضارات المصرية والأدومية واليونانية والرومانية. فالديانة النبطية كانت قائمة على التعددية في المعبودات ، وهي من ولن ولن

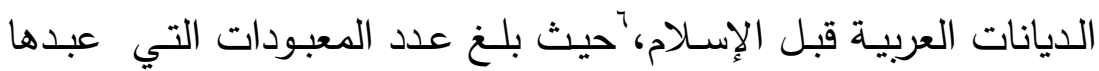
الأنباط عشرين معبوداً، وقد حظيت كل تلك المعبودات بالتقدير والاحترام

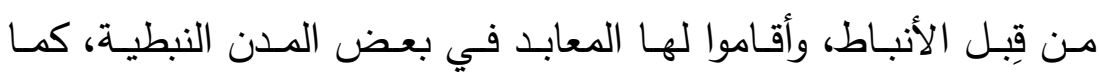
استحدثوا نظاماً تشريعياً دينياً يختص بفرض وض الغرامات وتطبيق اللعنات علي من يخالف هذه القوانين والتشريعات الدينية. ^

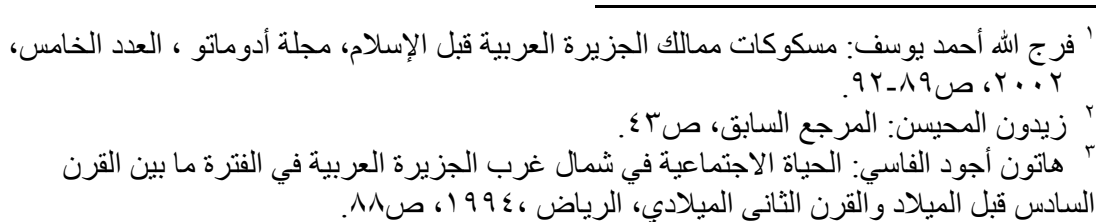

${ }^{4}$ Hammand ,C,P "The Nabataean ;Their History, Culture and Archaeology, Sweden,1973,p86.

${ }^{5}$ Healey, J,F, op ,cit p181.

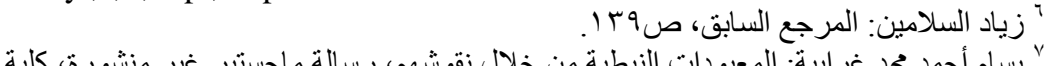

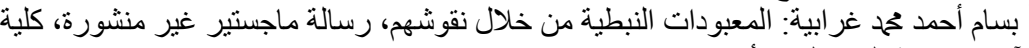

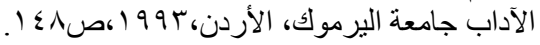




\section{عوامل تطور الايانة النبطية}

هنالك عدة عوامل سـاعدت علي تطور ديانـة الأنباط أولها العامل

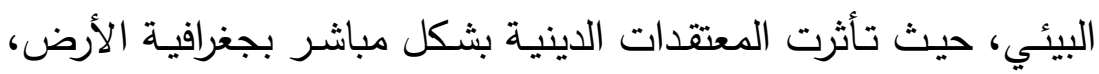

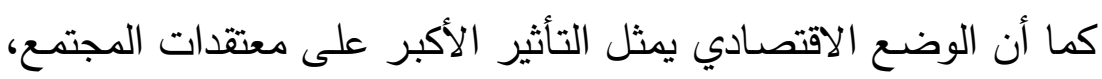

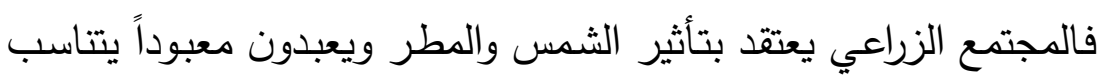

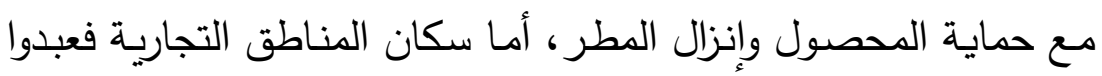

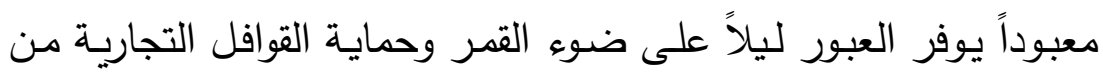

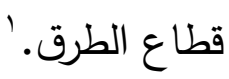

انتقل الأنباط من حياة البداوة إلى حياة التحضر والتمدن ، حيث كانوا

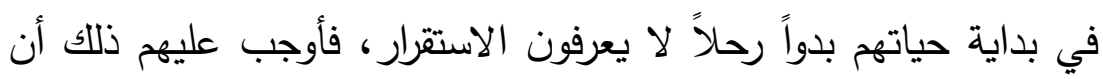

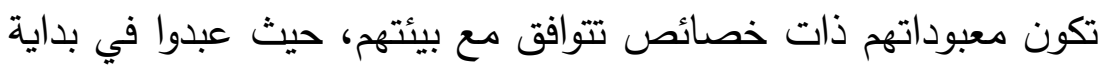

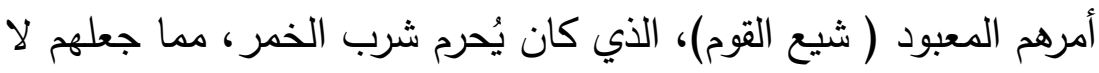

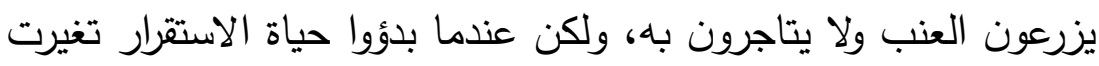
طبيعة التفكير الديني عند الأنباط، فعبدوا المعبود ذو الشرى ولهن الذي يسمح

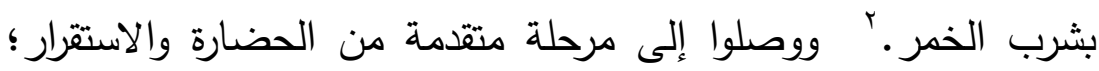

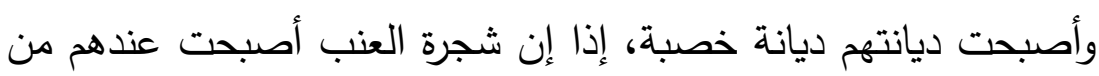
الخصائص المميزة للفن النبطي.

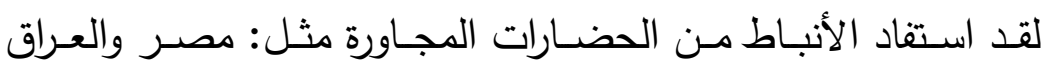
واليونـان، واقتبســوا بعـض خبـراتهم في اسـتخدام نظـم القــوات والميـاه

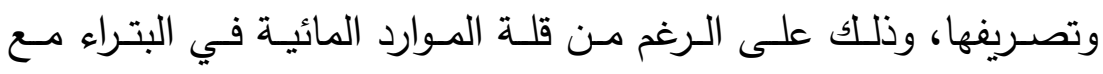
التضاريس القاسية، وهذا ما دفع الأنباط إلى الابتكار في مجال استخدام

' أحمد أمين سليم: جو انب من تاريخ وحضارة الجزيرة العربية في العصور القديمة، الإسكندرية،

2 Healey, J,F, op ,cit p144.

${ }^{1}$ Glueck.N. " Anew la Discovered Nabataean temple of Attar gates and Had ad at Khirbiet et - Tannur, Transjrdanian" In A J A, vol 41, part 3, 1937 ,p 363. 
مجلة كلية التربية ـ جامعة الإسكندرية المجلد السادس والعشرون (العدد الخامس أ) لسنة 17 ب ץ

المياه وتخزينها.' ولقد كثفت الآثار عن وجود أنظمة متقدمة عند الأنباط

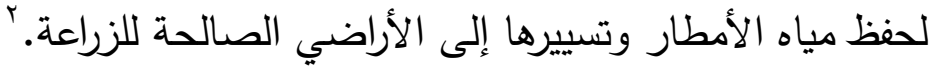

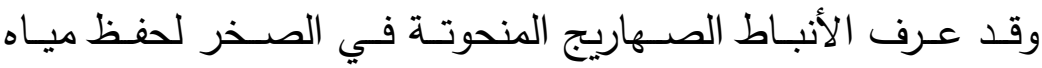
الأمطار ، وقد عثر على العديد من الآبار والقنوات، وخاصة في مدينتي

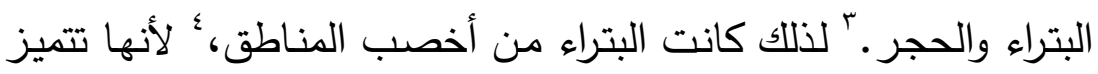
بكثرة مياهها العذبة التي تتجمع في صهاريج من مياه مجاري السيول، مما جعلها ذات أهمية تجارية كبيرة حيث تجد فيها القوافل التجارية مكاناً للراحة والتزود بالماء والطعام.

وقد شهدت البتراء نهضة زراعية كبيرة في عهد الأنباط، وذلك نتيجة

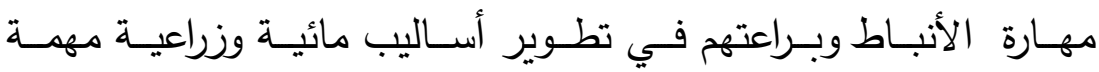

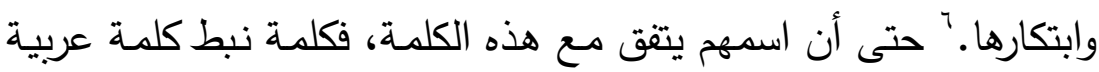

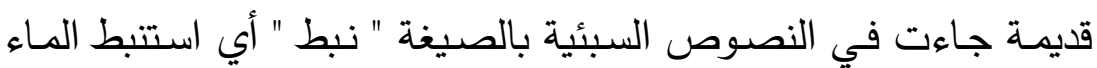

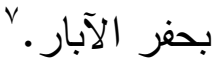

أما العامل الثاني الذي ساعد في تطور ديانة الأنباط؛ فكان العامل التجاري، والذي كان لـه تأثير مباشر على الحياة الدينية، حيث ظهرت

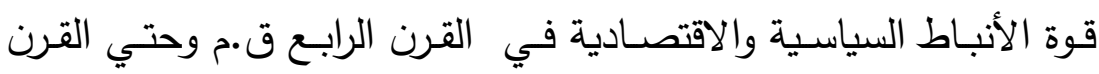
الثاني الميلادي، وبدؤوا يتواصـلون مـع جيـرانهم، ولاسـيما، أنهم كـانوا

${ }^{1}$ Charles.R .ortloff, " The Water Supply and Distribution System of The Nabataean City Of Petra Jorden,300 B.C- 300 A.D" Cambridge Archaeological Journal ,vol15, 2005,p93 -108.

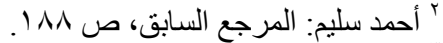

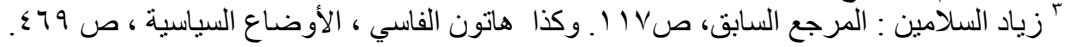

${ }^{4}$ N.S. Jaukowsky, ," Nabataean Petra" In: BASOR, vol,324, 2001p,1.

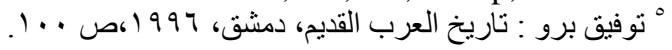

${ }^{6}$ Hanna Nydahl, "Archaeology and Water Management In Jorden, Uppsala University, 2003, p31-39.

${ }^{7}$ J. C .Biella " Dictionary of Old South Arabia ,Sabaean Dialect," Harvard,1982,p290. 
يسيطرون على طرق التجـارة، ولهم علاقـات تجاريـة مـع شبه الجزيـرة العربية وسوريا ومصر وبلاد اليونان والرومان.'

ووصلت مملكة الأنباط إلى درجة كبيرة من الاتساع التجاري قد ولد وماند

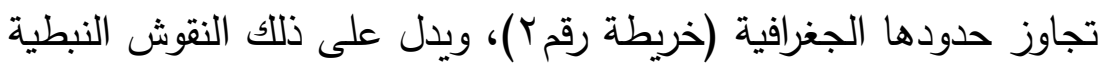

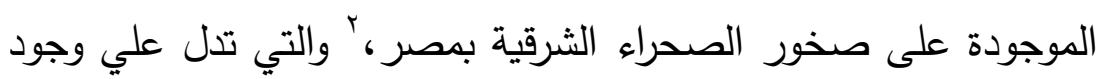

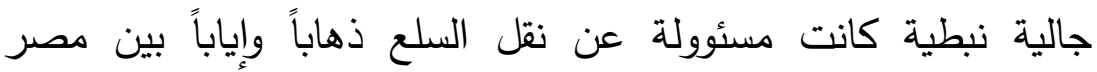
والبتراء، ووصل نفوذهم التجاري في حوض البحر المتوسط حتى وصل دهل إلي إيطاليا.

وهذا أدى إلى اكتسـاب الثقافـات وتبادل أنمـاط الحياة المختلفة فيما بينهم وبين شـعوب تلك الدول، فكان لـه تأثير على حياتهم السياسية والدينيـة.ؤذلك مـن خـلال الحركـة البشرية التي حملت معهـا الأفكار

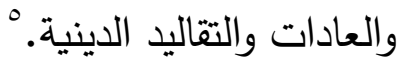

وكان من الطبيعي أن يؤثر الأنباط ويتأثروا بالثـعوب التي تعاملوا

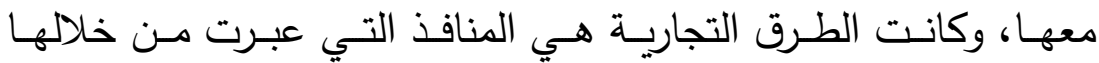
التأثيرات الدينية، لذلك فإن طرق التجارة لم تقتصر على نقل البضـائع والسـلـع التجاريـة فحسـب، بـل انتقلـت عـن طريقهــا المظــاهر الدينيـة

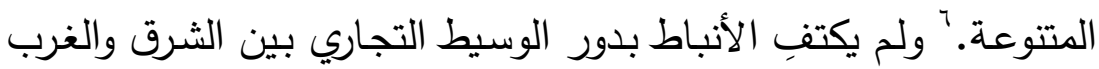
مستفيدين من موقعهم الإستراتيجي على طرق التجارة الدولية، بل صاحب لهب

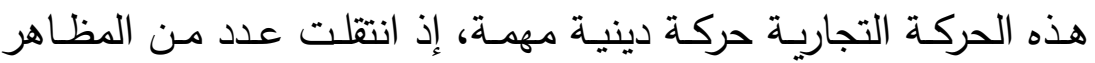

${ }^{1}$ A.L Bedal, Op Cit ,p11.

؟ عبد الدنعم عبد الحليم سيد: صلات الأنباط بمصر ، مجلة كلية الآداب و العلوم الإنسانية، جامعة الملك

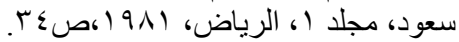

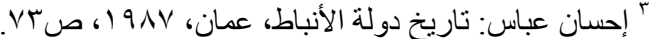

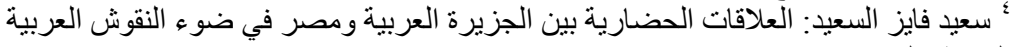

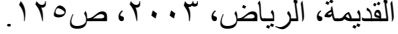

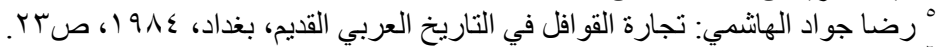

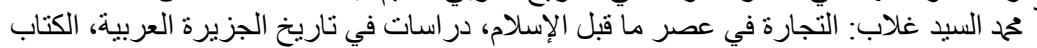


الدينية المختلفة إلى الثعوب التي كانت تتاجر معها، وأثر بعضها في

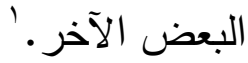

وكان العامل التجاري باعثاً قوياً على استفادة الأنباط من فنون الحضارات التي تعاملوا معها في المجالات المختلفة؛ وخاصة في التأثيرات الدينية، لذا ظهرت ملامح التأثيرات المختلفة في ديانة الأنباط، وقد تمثلت في أهم آثار الأنباط، في مجموعة المحاريب التي احتوت على رمز المعبود "ذو الشرى"، وهي عبارة عن كتلة صخرية مستطيلة

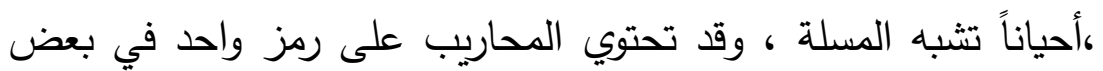
الأحيان أو تحتوي على عدة نماذج لرمز المعبود، وأثشر المحاريب

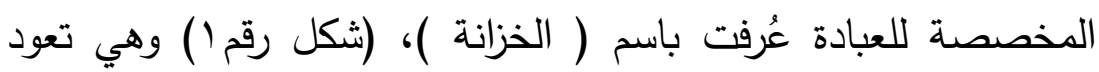
للقرن الثاني الميلادي، وسميت بذلك لاعتقاد الناس بأنها تضم كنزاً

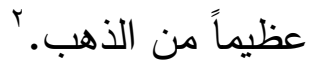

وهكذا فقد صاحب الحركة التجارية حركة دينية أثرت تأثيراً مباشراً علي الشعوب التي تعاملوا معها، وأن تطوير هذه العلاقات كان يتطلب

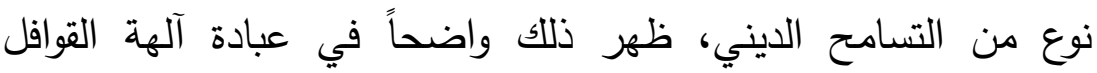
التجارية والتي ارتبطت بالقوافل والمحطات التجارية التي ينزلوا بها.

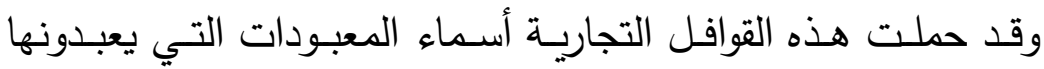
لحمايـة القوافل، فكان ذلك سبيلاً لنشر أسماء المعبودات داخل الجزيرة

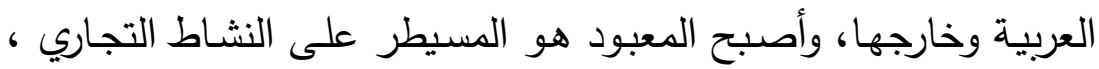

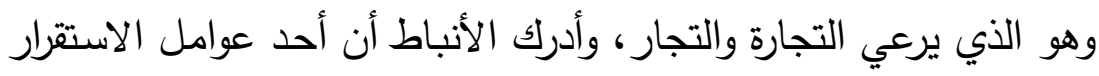
والازدهار هو تجارتهم الخارجية؛ لذلك سارع العرب من جنوب الجزيرة

' بورة عبدالله النعيم: الوضع الاقتصادي في الجزيرة العربية في الفترة من القرن الثالث قبل الميلاد

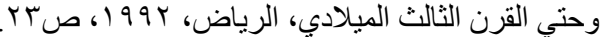

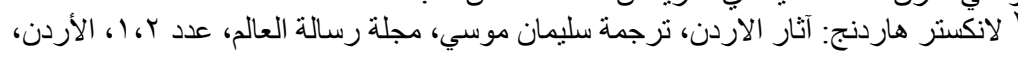
${ }^{3}$ Doe ,"the WD,B Formula and the Incense Trade" in P.S.A.S., vol 9 , 1979, p40. 
العربية وشمالها وشرقها وغربها إلى استغلال ذلك الأمر على أحسن

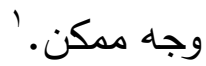

ونتج عن ذلك النشاط التجاري أنشطة أخرى تمثلت في تربية الخيول

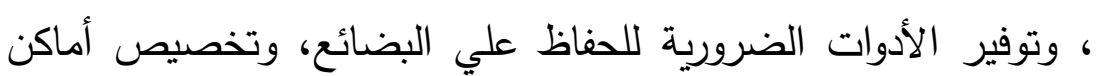

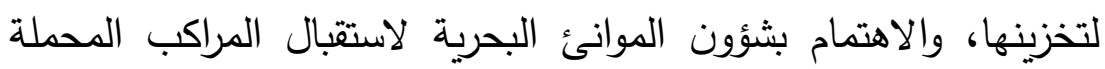

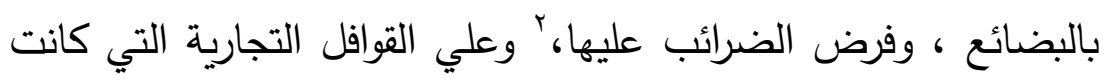

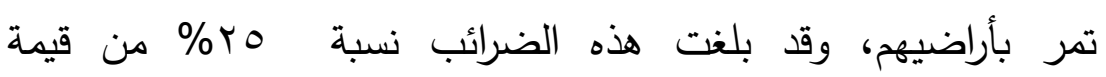
البضائع.

وكان العامل السياسي هو ثالث هذه العوامل، حيث كان له تأثير قوي يفرض سيطرته على الحياة الدينية في المملكة النبطية التي اتبعت نظاماً

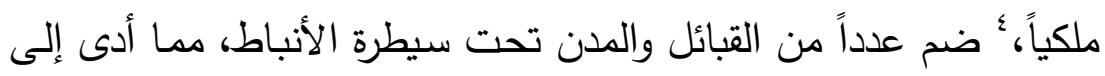

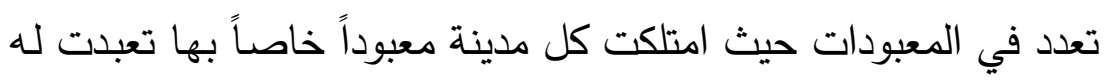
وتقربت إليه،، وعندما وقعت تحت سيطرة الأنباط احتفظت بمعبوداتها المحلية، بالإضافة لعبادة المعبودات النبطية، كما شهدت مملكة الأنباط علاقات مع الدول المجاورة تراوحت بين شد وجذب وسلم وحرب.

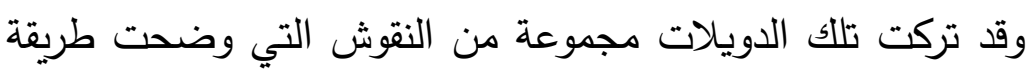
انتقال المعبودات بينهم ، ففي حالة الحرب تحمل كل دولة معها

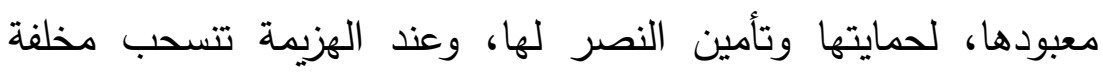
وراءها تمثال معبودها، فيقوم المنتصربضمه إلي مجموعة المعبودات

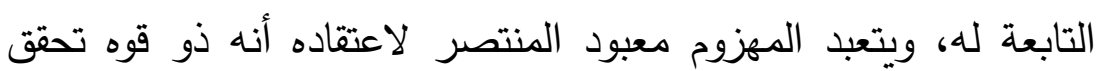

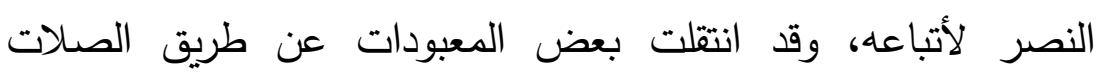

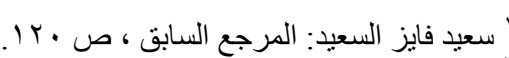

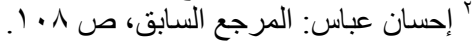

${ }^{3}$ H.M. Catton," Land Tenure in the Documents From the Nabataean Kingdom and the Roman Province of Arabia" in Z.P.E, Band 119, 1997m p 255 -265.

4 Alfassi. H, "Nabataean and her Woman" in S.A N H.S ,vol4,n.2, 2001, p, 15.

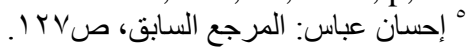


مجلة كلية التربية ـ جامعة الإسكندرية المجلد السادس والعشرون (العدد الخامس أ) لسنة 17 ـ ب

التجارية؛ وخاصة في مملكة الأنباط.' ونتج عن ذلك انتقال المعبودات الخاصة بالشعوب الأخرى، عن طريق التجار القادمين منها، واستقروا

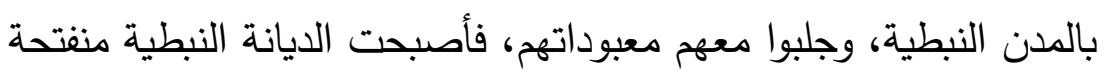
على الايانات الأخرى فتأثرت وأثرت.

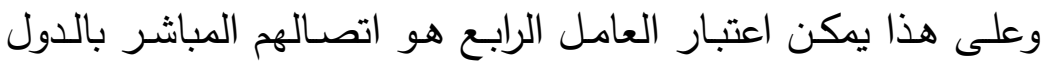

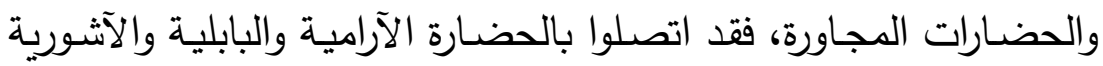
واليونانية والرومانية، وقد ظهر ذلك واضحاً في انتقال معبوداتهم ورموزها

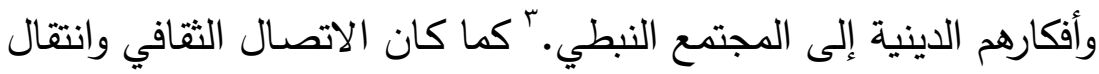

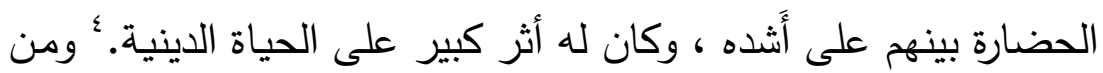

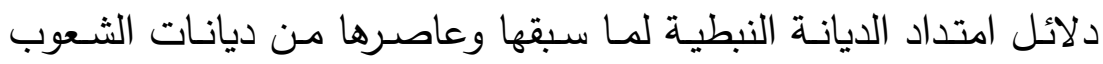
الأخرى، وجود فكرة التثليث مجسدة في الكواكب السماوية، حيث يتكون

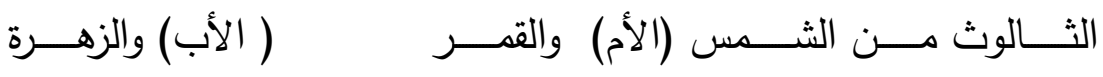

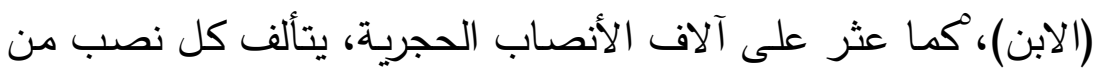

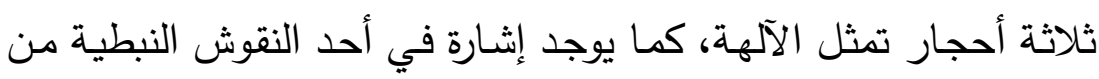

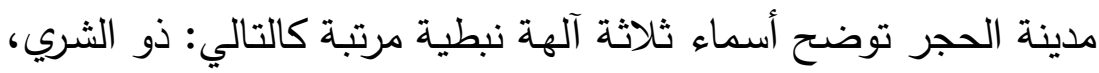

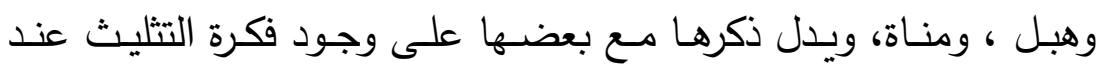
الأنباط، وهن

و يذهب جواد علي إلى أكثر من ذلك، ويري أنهه مـا من اسم من

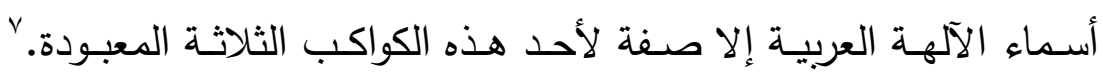

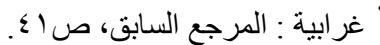

${ }^{2}$ Alpass .p .j, " The Religious Life of Nabataean Durham theses, Durham University, 2011,p,70.

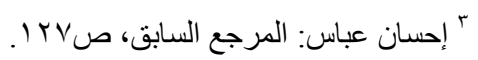

${ }^{4}$ Wenning, R, " The Nabataeans In History Polities, the World of the Nabataeans" in K.D. Palitis vol 2, Stuttgart, 2007,p,31. 
بينما يختلف معه (بيستون) ويرى أنه ليس من الضروري أن تكون معظم الآلهة العربية منسوبة إلى الثالوث الكوكبي القائم على عبادة النجوم.' هذا وقد تعـدت المعبـودات التي عُبدت في الجزيـرة العربيـة بـين معبودات فلكيـة كالثمس والقــر والنجوم، ومعبودات طبيعيـة كـالمطر

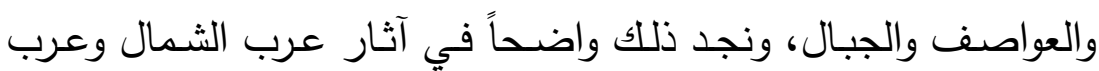
الجنوب ، ولقد امتاز النظام الديني النبطي بالحفاظ على الوحدة الدينية

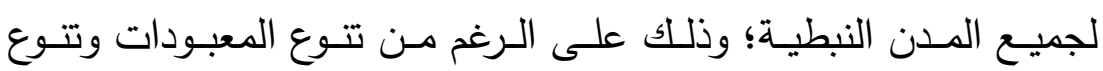

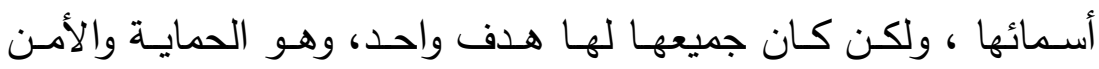
والسعادة.

لقد تمكن الباحثون من معرفة أسماء بعض المعبودات، والمعتقدات الدينية؛ وذلك من خلال الكثف عنها في التنقيبات الأثرية في حفريات موقع خربة التتور في وادي الحسا في الطفيلة، وحفريات خربة الذريح، حيث تم الكثف عن عدد كبير من الآلهة التي تمثل الأبراج والآلهة

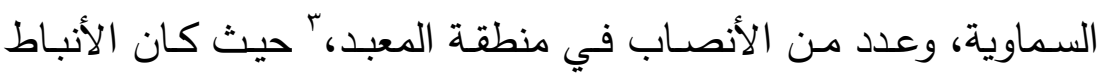
يحجون إلى معابدهم الموجودة في المناطق المرتفعة مثل: خربـة الذريح وخربة التنور، وكانوا يطوفون حول المنطقة المركزيـة في المعبد ، أثناء إقامتهم لطقوسهم الدينية. وقد عبد الأنباط العديد من الآلهة التي عُبدت قبل الإسـلام ، وكان التهان

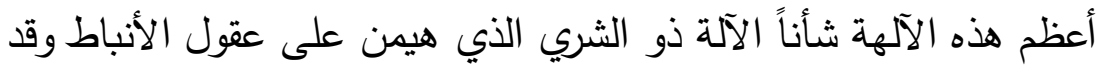

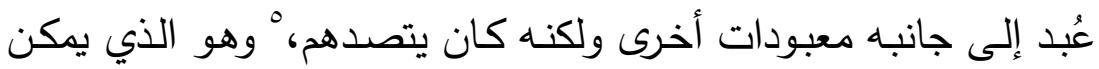

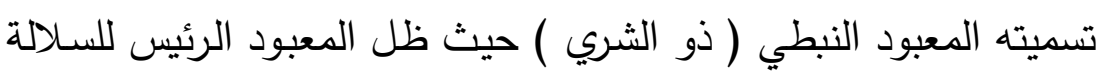

${ }^{1}$ Beeston," The Religions of Pre- Islamic Yemen "L, Arabia du Sud. Histora et Civilization" Tome 1, La duple Yemenite, Paris, 1984, p,260.

${ }^{2}$ AlPass ,P,J , Op, Cit, p 25. 
الحاكمة، وكانت له سيطرة كبيرة، وهو المعبود الوطني، وأن الأنباط قد

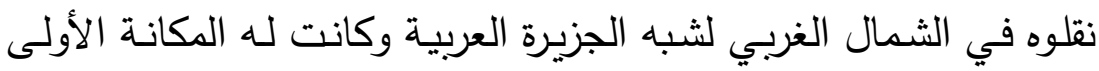

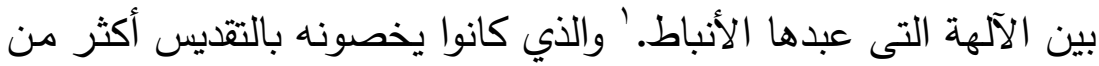

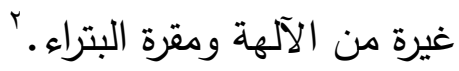

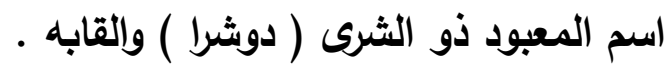
يتألف اسم المعبود ذو الشري من مقطعين أحدهما: ( ذو)، والآخر ( الشري)، وذو تعني صاحب أي صاحب الشري، والشرى اسم لموقع دون

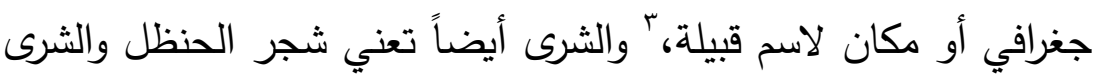
موضع تتسب إليه الأسود ، فيقال للشجعان، وما هم إلا أسود الشري.

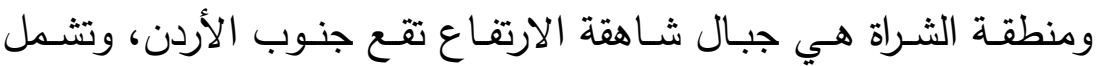
المنطقة الواقعة بين الحجاز واليمن، وقد استوطنت هذه المنطقة قبائل

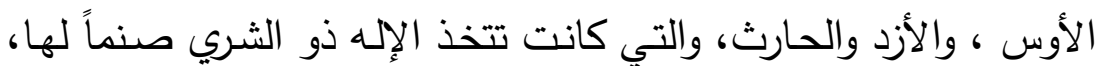
وقد هـاجرت هذه القبائل مـن اليمن إلى منطقـة السـراة بعد انهيـار ســ لهـ

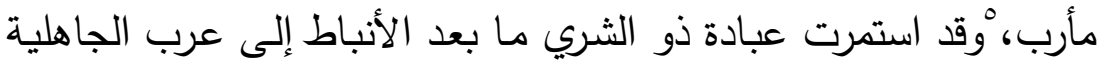

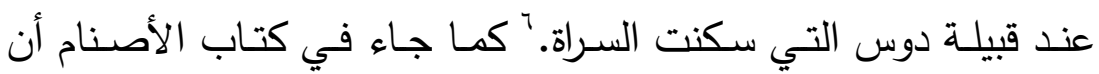

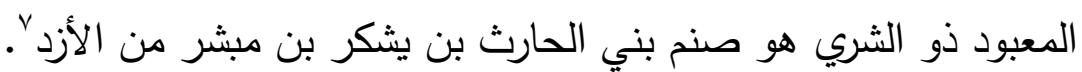

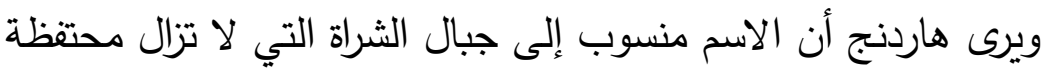
بهذا الاسم.^ وذو الشري تحريف للفظ الآرامي (دوسر) أما الاسم أعرا، الاسئ ترال فهو الاسم الآرامي القديم، وقد أطلق على ذو الشري اسم ذو الشري

${ }^{1}$ Healy J,H, Op .Cit,P186.

${ }^{3}$ Teixidor, 1977,p,83 .

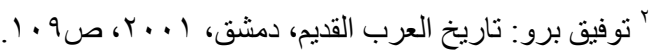

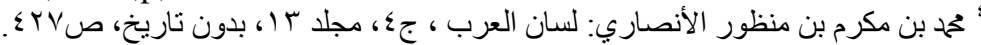

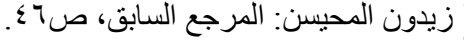

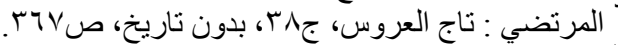

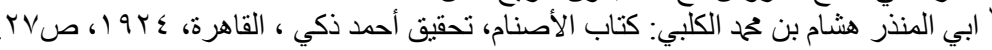

${ }^{8}$ Browning, 1980, p44. 
أعرا.'فأعرا هو الاسم الآرامي القديم لذو الشري، وهو لقب عربي أطلقه

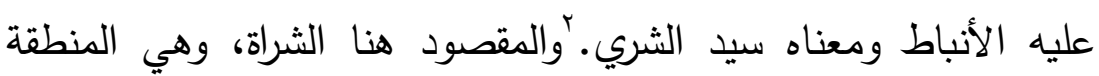

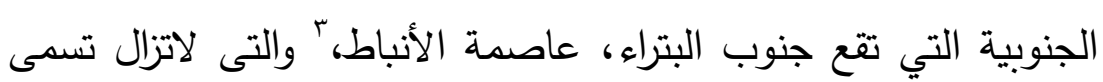
كذلك حتى اليوم.

من خلال ما سبق يتضح أن معظم الباحثين يرون أن ذو الشري له

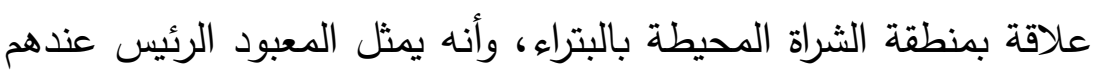

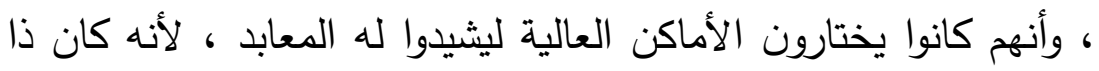

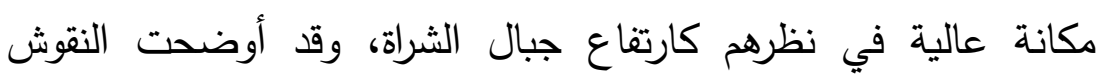

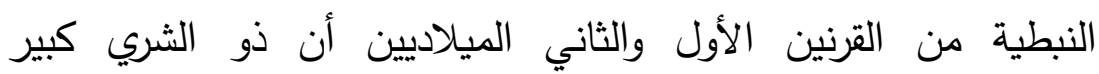
المعبودات النبطية.

مما يدل على الاعتقاد بوجود معبود عالٍ فوق كل شيء، وهو المهيمن والمسيطر على العالم، وقد كان هذا الأمر ظاهرة شاملة إقليمياً،

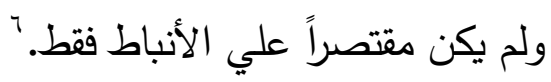

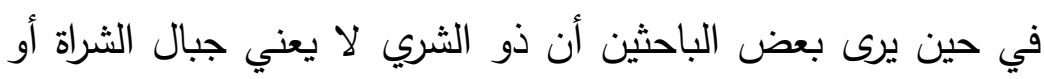

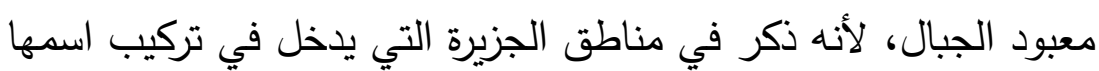

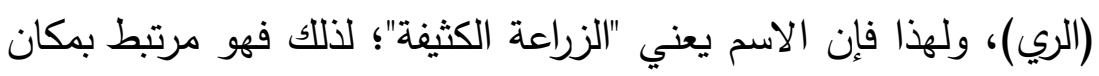

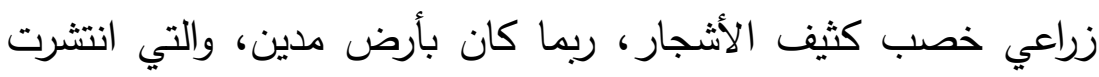

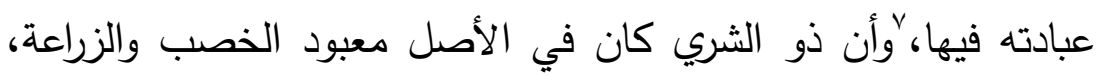

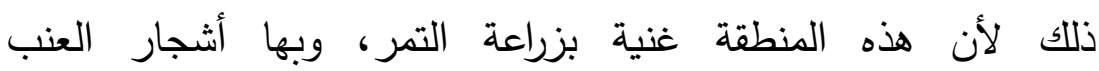

${ }^{3}$ Healey, op.cit,p86.

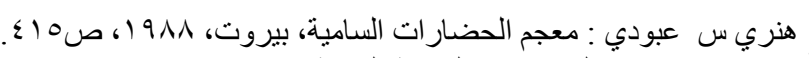

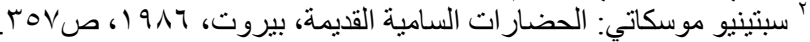

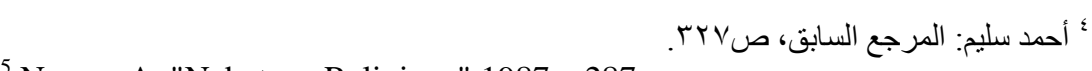

${ }^{5}$ Nagav ,A ,"Nabatean Religions" 1987,p,287 .

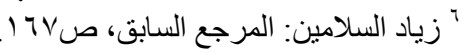

${ }^{7}$ Bosworth ,c,E,"Modyan Shu,aub in Pro-Islamic and Early Islamic-land on History" in J S S , vol 29, 1984,p,55 .

وكذا أحمد سليم: المرجع السابق، ص وrr. 
والزيتون.'حيث تميز المعبود ذو الشري بوجوده بالقرب من الماء، ووجدت له أماكن في وادي فرسا، وسد المعاجيل، ومناطق المذبح، وكلها أماكن مقدسة يوجد فيها خزانات للمياه.

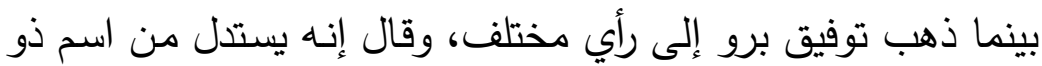

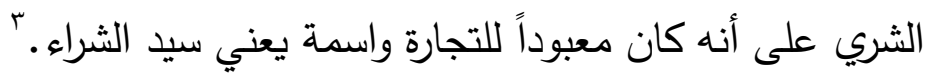

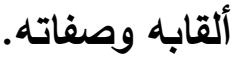

كان ذو الشري المعبود الرئيس عند الأنباط، وقد عُبد في العديد من المناطق النبطية، ويرى بعض المؤرخين أنه كان معبوداً للخضرة والسماء

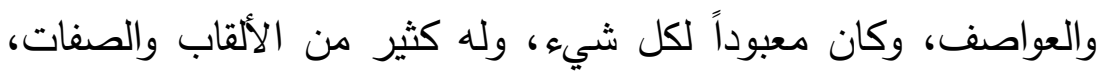

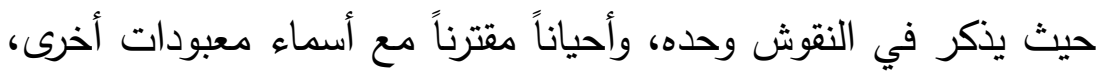

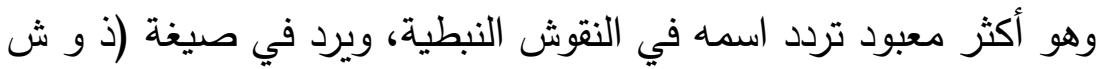

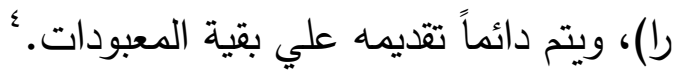

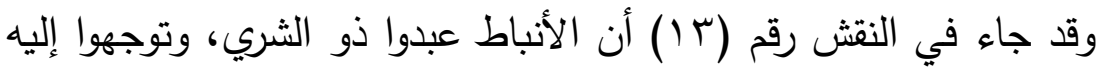

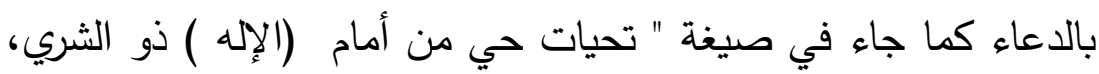
ومن النقوش ما وصفته بأنه صاحب قوه دينية يعاقب ويلعن ويحرم كما هاء جاء في النقش ( T Y )" فليكن معه لذو الشرى الإله للتحريم غرامة قدرها

${ }^{1}$ Beeston ,A,F,L," The Man of The Tongle Wood In The Qur,an "in J S S Vol 13,1968.

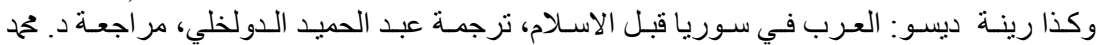

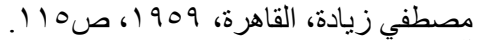

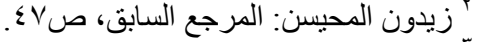

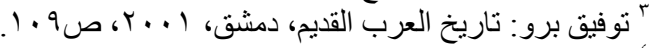

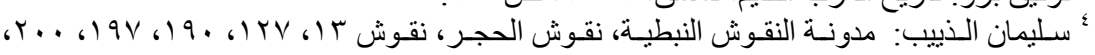

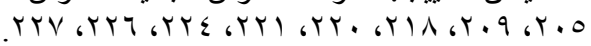


ألف قطعة حارثية" وذكر في أحد النقوش أنه سيد جميع المعبودات حيث

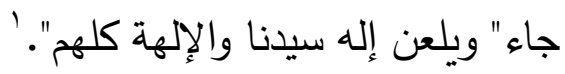

ويتضح من هذه النقوش أنه كان معبود الدولة الرسمي، كما أطلق عليه" ذو الثري إل رب إيل ملك الأنباط".

وقد وصف ذو الشري في النقوش بالعديد من الصفات، فهو سيد

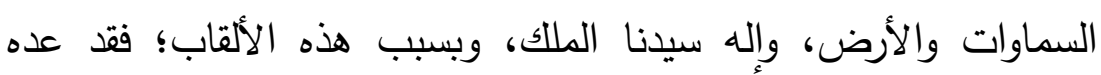

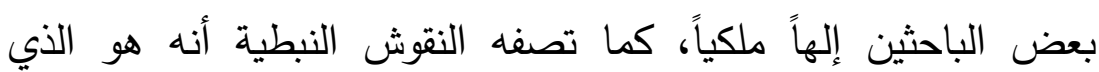

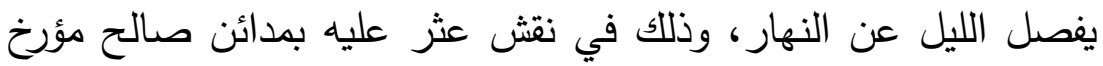
لعام عم حيث جاء فيه " فرس ليليا من يمما" وهي تعني فاصل الليل من

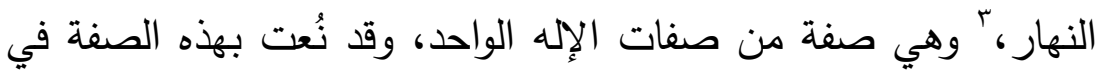

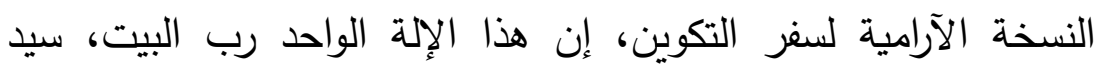

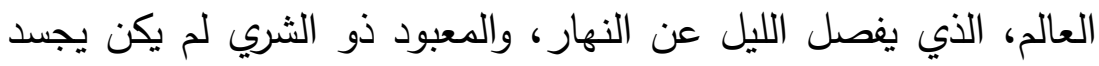

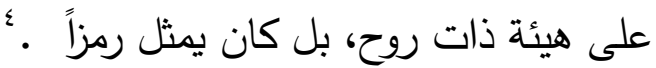
كما أطلق عليه في أحد النقوش" ذو دانيه دات لشري إله مدرسا"، وقد وجُد هذا النقش في منطقة المدرس قرب منطقة باب السيق، ويقصد بإله المدرس

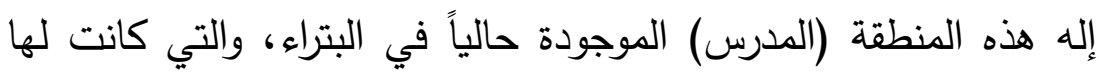

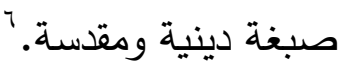

كما وصف أنه إله جايا، أي وادي موسي، وذلك في نقشين أحدهما :من النقب، والآخر: من دومة الجندل، كما جاء هذا الاسم في كثير من ودئ

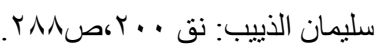

${ }^{2}$ Negev ,A," A Nabatean Archaeology To day" ,New York,1986,p,107.

و وكذا Milik, J, T," Nouvelles Inscription Nabateennes" in Syria, vol 35, No 314, 1958,p,231,

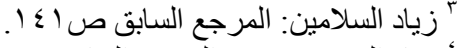

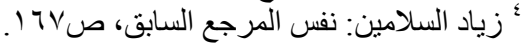

${ }^{5}$ Healey, op .cit, p,91.

$$
\text { " زيدون المحيسن: المرجع السابق، صV؛ . }
$$


أسماء الأعلام مثل:" عبد الجا- عبد الجيا" وخاصة في الرقيم حيث تقام مساكن الجي وسط أطلال الرقيم، ولا زالت قائمة إلي اليوم، وجيا بالعبرية تعني "وادٍ أو مدر سهلي" ولهذا الاسم معنى إلهياً يجعلة صفة أو لقباً لذو الشري، فعند تسمية عبد الجا؛ فهي تعني عبد ذو الشري، وهناك من يربط الاسم بوادي موسى مكان عبادة ذو الشرى أو مكان معبده.

كما عثر على نقوش نبطية في وادي رم تصف هذا المعبود بأنه" م ر 1 ب ي ت ا"، أي سيد البيت وراعية، و" ب ي ت ا"، وهنا تعني مكان

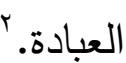

هذا ويعتقد أن المعبود ذو الشري ما هو إلا امتداد للمعبود" ذو غابة" وأنه كان يمثل إله الثمس عند الأنباط، بدليل إقامة عيد لله في كانون الأول من كل عام، وذذلك في الفترة المتأخرة، حيث ارتبط بالإله زيوس Zeus وارتبط بالثمس، وأصبح إلهاً شمسياً. ؛وفي العصر الروماني اقترن ذو الثرى بالإله ديونيسيوس وباخوس،ومارس وجوبيتر، كما اقترن بالإله شمين، والإله بعل، وحدد في الديانات السامية. شكله وهيئته: (- شئه

${ }^{1}$ Knouf \& Brooker ,ch," Dushara Of Gaia \&his Sanctuary" in P.S.A.S, vol 29, 1990,p,4ff.

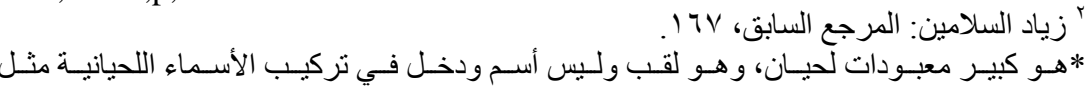

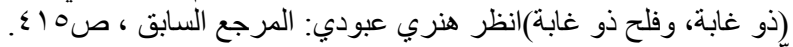

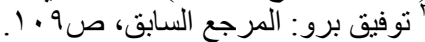

4 Starcky ,J," Petra et la Nabateene," Supplement au dictionnaire la Bible,vol V11,1966,p,913.

5 Fahd ,T," La Pantheon de Arabia Centrale Le ala Vielle de L, Hegire,paris, 1968,p,71.

6 Hammond, P,C "The Nabataeans "Gothen burg,1973,p,95. 
كان الإله ذو الشرى يمثل - بشكل رمزي - الطريقة الرمزية التي اتبعها

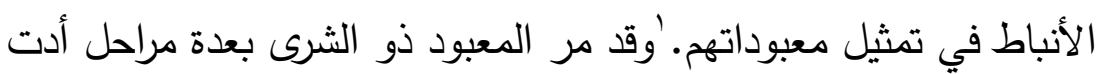
في النهاية إلى تطور أشكاله من وقت إلى آخر ، وذللك حسب التب التطورات التي مر بها الأنباط، وتطور المعبودات التي عبدوها، حيث كان المعبود ذو الشرى في البداية عبارة عن حجر مربع أو مستطيل، لونه أسود، وله

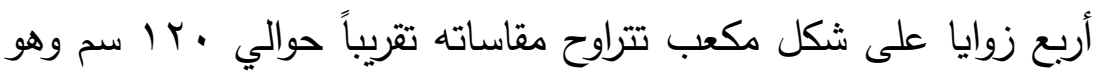
ما يعرف باسم (Betyls ) عند اليونانيين، وهي مشتقة من الكلمة السامية ( أي بيت إيل بمعنى بيت الإله، وهذه الأحجار (Beth - El )

تتكون من نوعين أحدهما: نوع ثابت والآخر نوع منقول، والمنقول عبارة

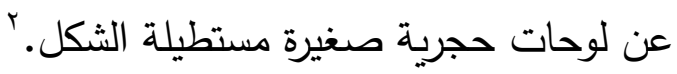
في بداية الأمر لم يكن بها أي زخارف، ولكن بعد ذللك نقش عليها

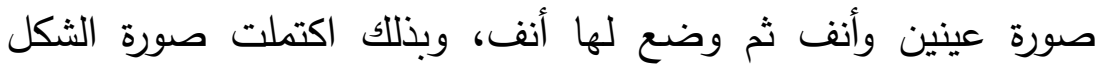
الأدمي “كما كانت هذه الأحجار المنقولة صغيرة حتى يمكن حملها والتتقل بها من مكان إلى آخر ، وهو ما يتناسب مع حياة التتقل والترحال

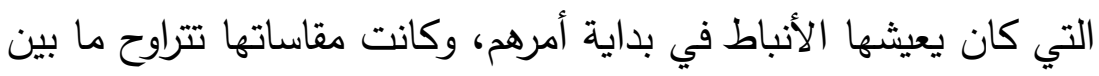

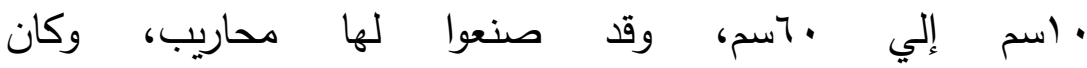
الحجر يؤضح في الدحراب ليتعبد له ثم يحمله بعد الانتهاء من العبادة.

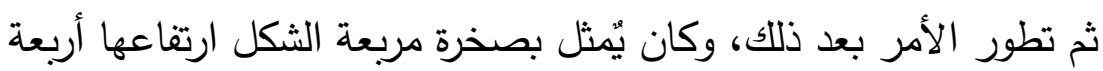

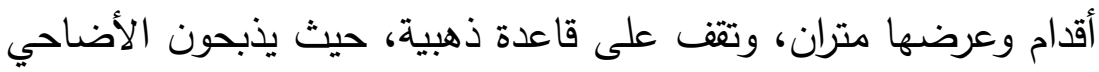

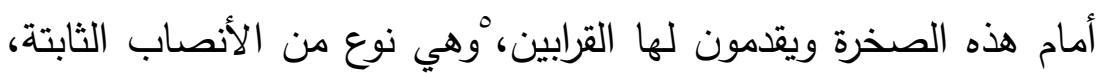

\footnotetext{
${ }^{1}$ Avner,U ," Nabataen Standing Stones" 2000,p,109.

${ }^{2}$ Wenning ,R," The Betyls of Petra" ,in A. S. O. R, vol 324, 2001, p, 80.

${ }^{3}$ Patrich,J," The Formation of Nabataean Art, Prohibition of A Graven Image a many The Nabataeans" The Hebrew university, Jerusalem, 1990,p, 84.

${ }^{4}$ Wenner ,R, Op.cit,p,86.

${ }^{5}$ Avner,U op . cit,p,99.
} 
مجلة كلية التربية ـ جامعة الإسكندرية المجلد السادس والعشرون (العدد الخامس أ) لسنة 17 ـ ب

أو المسلات المنحوتة على شكل مربع منحوت من الحجر الرملي، وكانت خالية من أي أشكال رمزية، ومن تصوير المعبود بصور تماثيل آدمية أو حيوانية، وهي تتناسب مع تللك المرحلة المبكرة للديانة النبطية،

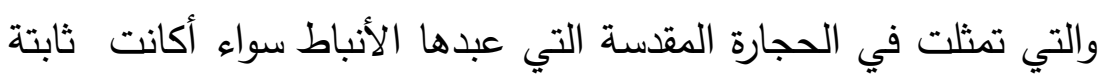
أم منقولة.

ونتيجة التواصل الحضاري للأنباط والانفتاح على الحضارات الأخرى

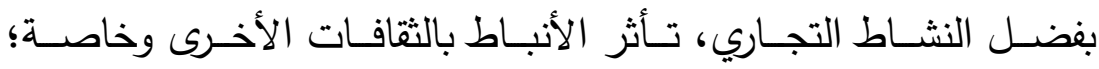

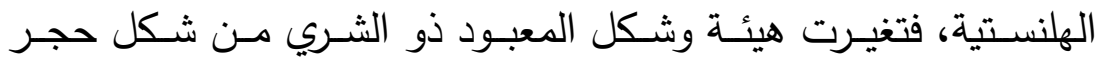
مستطيل إلى هيئة بشرية،(شكل رقم r) بعد أن كان نصباً حجرياً واقترن

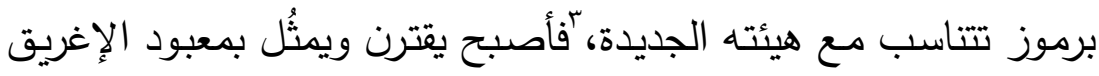

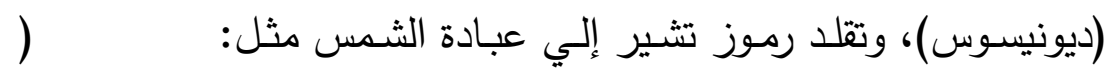

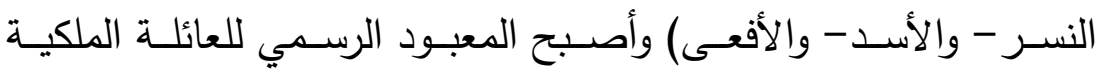
النبطية.

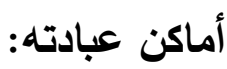
اهتم ملوك الأنباط بتوفير أماكن لعبادة المعبود ذو الثري في معظم

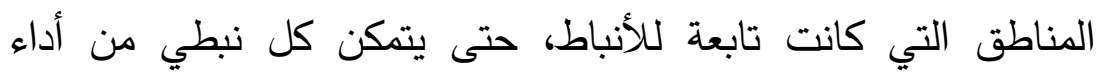

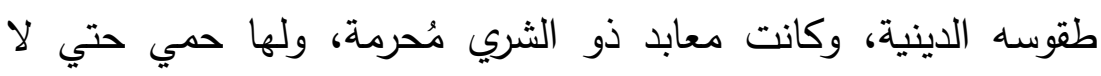

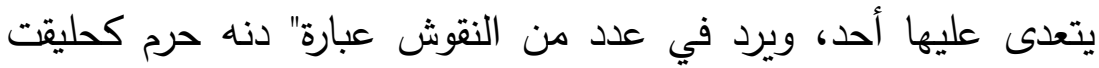
حرما دي محرم لدوشرا" بمعني إن هذا القبر محرم كحرمة حرم ذو

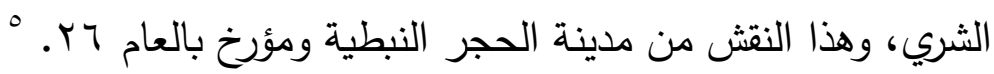

${ }^{1}$ Patrich,J, op .cit,p,59.

${ }^{2}$ Wenning,R, op . cit ,p,79.

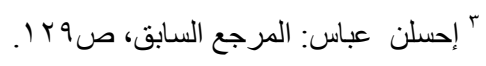

${ }^{4}$ Hammond,c,ph, op. cit ,p,88. ززياد السلامين: المرجع السابق، ص109. 
وكـان أكبر معبد لـذو الثـرى بـالرقيم، وهـو المســى قصـر البنـت

( شكل رقمץ) (قصر بنت فرعون ).'ويقع هذا المعبد في وسط مدينة وهرية

البتراء، وارتبطت تسمية هذا المعبد باسم "بنت فرعون" بعادة قديمة عند

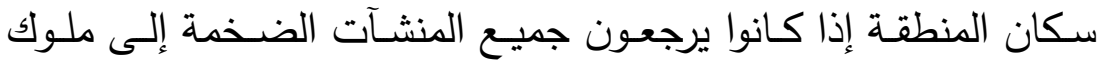
مصر القدماء، ومن بين أشهر هذه المنشآت (الخزنة) وتسمى خزنة

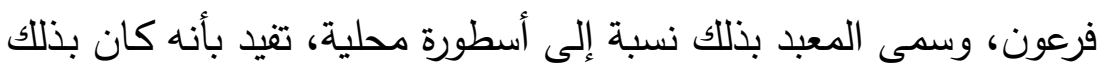

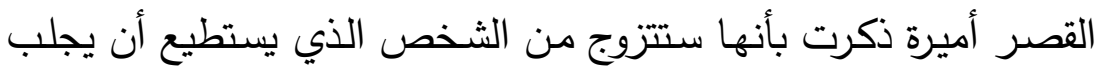

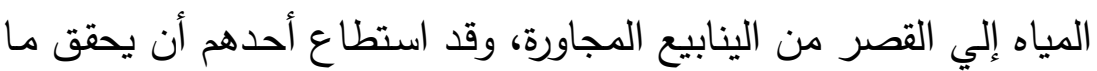

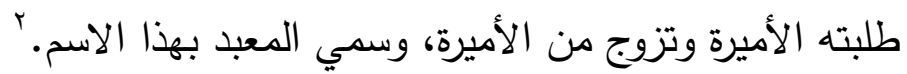

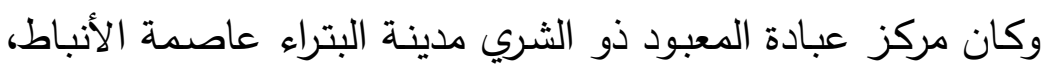

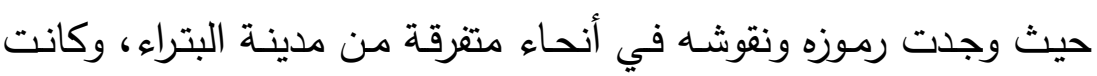

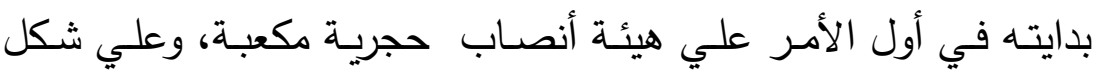
مسلات، وصنعت له المحاريب في مدينة البتراه، " وفيها أيضاً شُيدت له له اله

المعابد، ومنها معبد "قصر البنت" الذي شُيد لعبادة المعبود ذو الشري. أما في مدينة الحجر التي تُعد ثان أهم المدن النبطية بعد البتراء، فقد فئد عثر فيها على نقوش، تدل على عبادة المعبود ذو الشري فيها، وهي

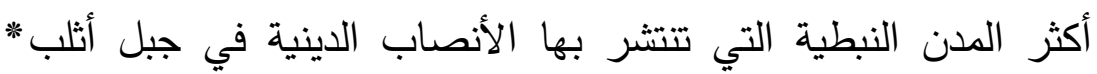

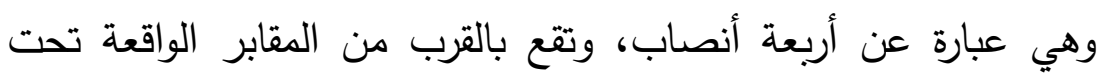

${ }^{1}$ Parr,P,J," Recent Discoveries in The Sanctuary of The Qasr Bint Far,un at Petra" in A.D.A.J, vol,12-13, 1967-1968,p,18.

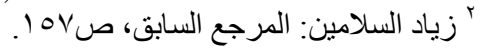

${ }^{3}$ Wenning, R, op. cit ,p,79.

${ }^{4}$ Haughton ,B, "Hidden History: Lost Civilization ,Secret Knowledge, and Ancient Mysteries", THE career Press ,New Jersey, 2008,p, 38.

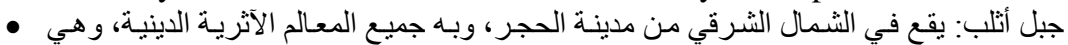

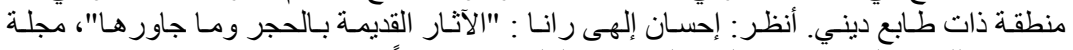

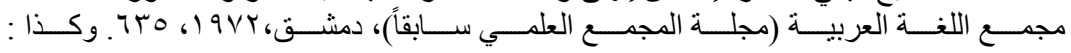
Nehme,L, , op .cit, p,656. 
مجلة كلية التربية ـ جامعة الإسكندرية المجلد السادس والعشرون (العدد الخامس أ) لسنة 17 ب ץ

حماية المعبود ذو الشري، والذي يُعد حامياً لتلك المقابر ، كما يوجد بها أنصاب لمعبودات أخرى ولكن ذو الثرى يتصدرهم في المكانة.' وتذكر بعض النقوش أنه من يخالف هذه الوصايا المكتوبة على دونى القبر، فإنه سيدفع غرامة مالية تُّفع للمعبود ذو الثري، حيث جاء

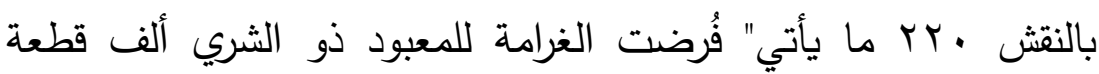

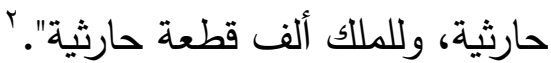

وفي دومة الجندل عُشر على نقش مؤرخ بالعام ع ؛، يشير إلى وجود

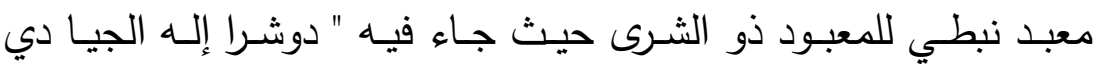

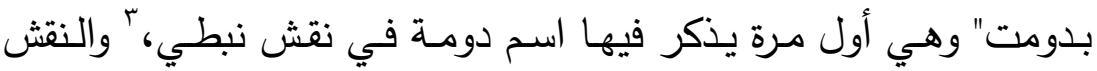
يتحدث عن تجديد معبد المعبود ذو الشري علي يد الكاهن مالك.

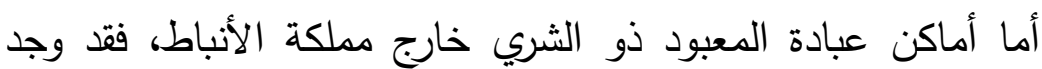
نقش نبطي له في مصر بمنطقة تل الثقافيةْ ( القريبة من التل الكبير) ، يدل على أن أحد أفراد الجالية النبطية، ويدعي "وهب الله" قام بيناء

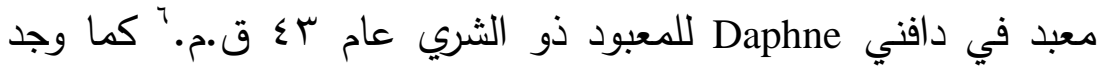
معبد يعود تاريخه لعامجاتقم في مدينة السويداء بسوريا، بناه الأنباط

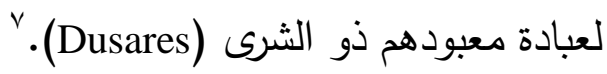

${ }^{1}$ Sachit, Zabeel, Rubbin christion Julion, "East and Mediterranean Sea Gods and Goddess in The Arab Region Pictures and explanations Documents and excerpt From The Workshop Held in Large quantities in France" Paris,2012,p,249.

${ }^{3}$ Nagev ,A, op .cit, p,10.

${ }^{4}$ Sovignac,R \& Starcky,J," Une Inscription Nabateenne Provenant De DJof" in R.B ,vol,64, 1957,p,215.

5 Richard,N \& Others," A Second Nabataean Inscription from tell eshshuqafiya ,Egypt" In BASOR,vol269,1988,p,53.

${ }^{6}$ Healey ,J, op .cit,p,9

ولمزيد من التغاصيل عن النقوش النبطة بمصر أنظر:

E. Littmann \& D. Meredith," Nabataean Inscripitions From Egypt" in BASOR ,vol 16,1954,pp211-46.

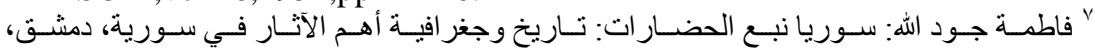
Or9 صن 1999 
وفي صيدا عثر علي نقش يشير إلي بناء معبد للمعبود ذو الثرى، يعود

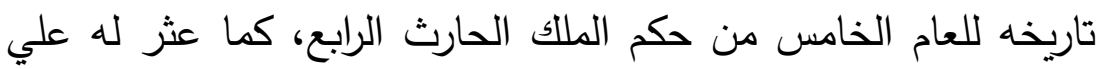
نقش نبطي في مدينة بتولي ( Puteoli ) القريبة من ميناء نابولي في

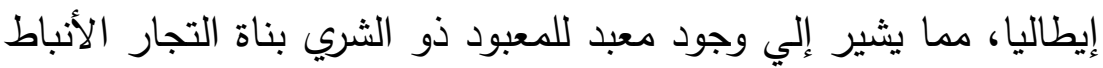

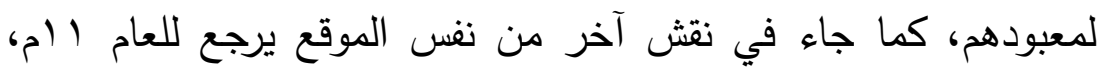

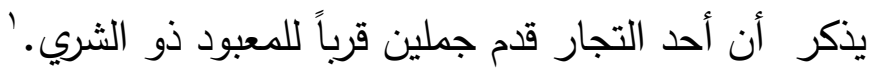
دور المعبود ذو الشري في الديانة النبطية:

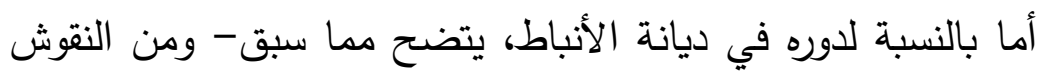

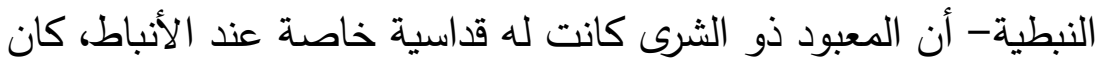

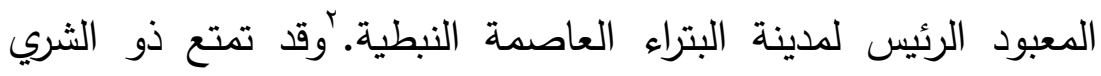

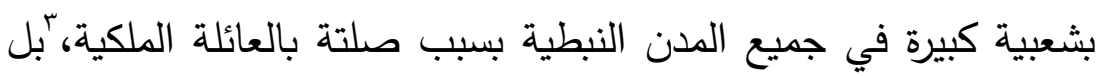
أن هذه القداسة لم تقتصر عليه فحسب، بل عدوا حتى الأماكن التي يعبد فيها أماكن مقدسة، وينسب إلى جبال الثراة المرتفعة، لأنه مرتفع المكانة

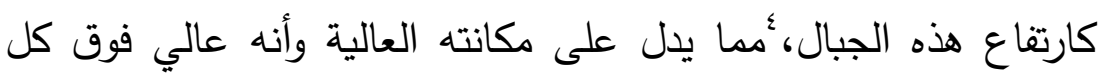

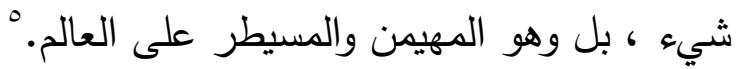
وتظهر هذه القداسة أيضاً من خلال تسميتهر لأشخاص بأسماء مثل:

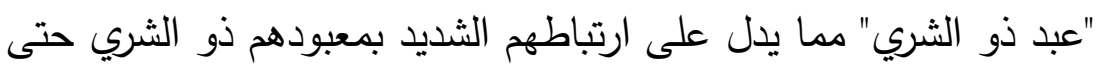

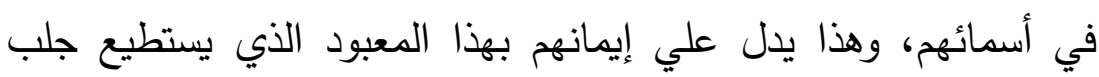

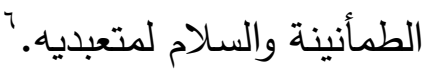

${ }^{1}$ Healey ,J, op .cit,p, 10.

${ }^{2}$ Wenning, R, op .cit,p, 30..

${ }^{3}$ Alpass ,P,J op .cit ,p,281 وكذا Hommond C,ph, op . cit,p, 89

${ }^{4}$ Negev, A, op .cit ,p, 287. 
كما تدل كثرة رموزه في البتراء على مكانته، فقد كان معبوداً للشمس، ولهذا نجد رموزه وأنصابه تتجه نحو المشرق، ومن رموزه البتره النسر والأسد

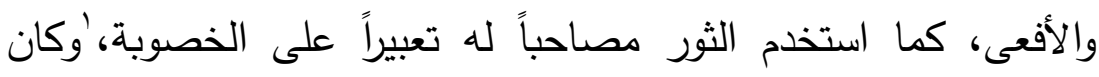

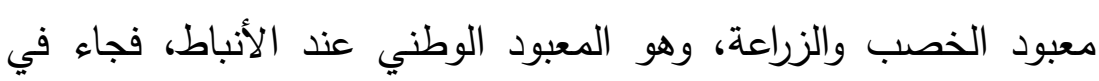

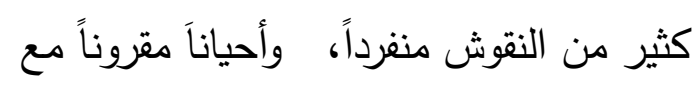

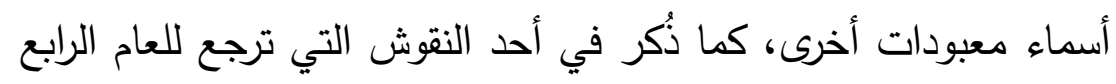

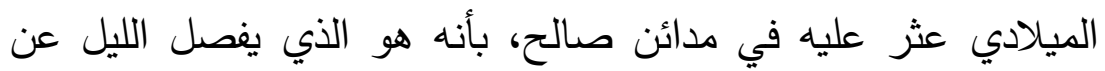
النهار. لقد تعبد الأنباط إلى العديد من المعبودات، ولكن كان أعظمهم المعبود ذو الشري، والذي هيمن على عقولهم، وظهر ذللك واضحاً من خلال

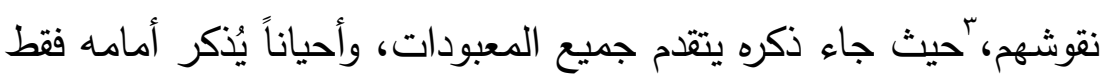

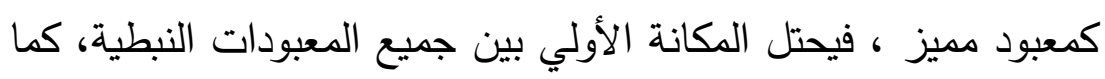

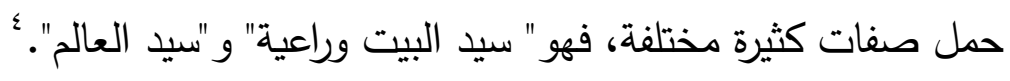

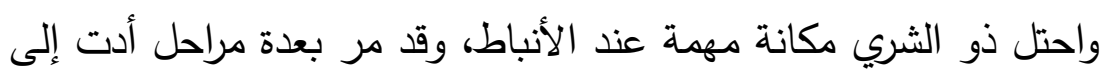

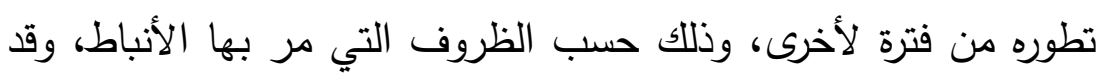
أخذ ذو الشرى من مظاهر تطوره من ديانات الأمم المجاورة، والدليل

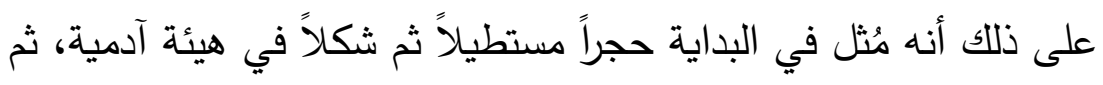
أصبح يقترن مع معبودات أخرى، حتي أصبح المعبود الرئيس عند فئه

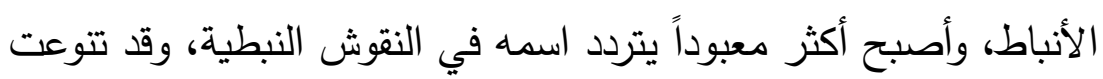

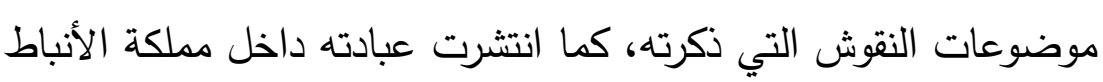

${ }^{3}$ Alfassi, H, op .cit,p, 12. 
وخارجها، فقد عُبد في البتراء، والحجر، ودومة الجندل، وحوران، وصيدا،

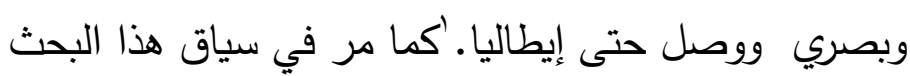
وعلى هذا فقد استمرت عبادة المعبود ذو الشري حتى بعد سقوط مملكة الأنباط، فكان المعبود ذو الشري من المعبودات الثائعة والمنتشرة في لفي

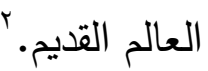

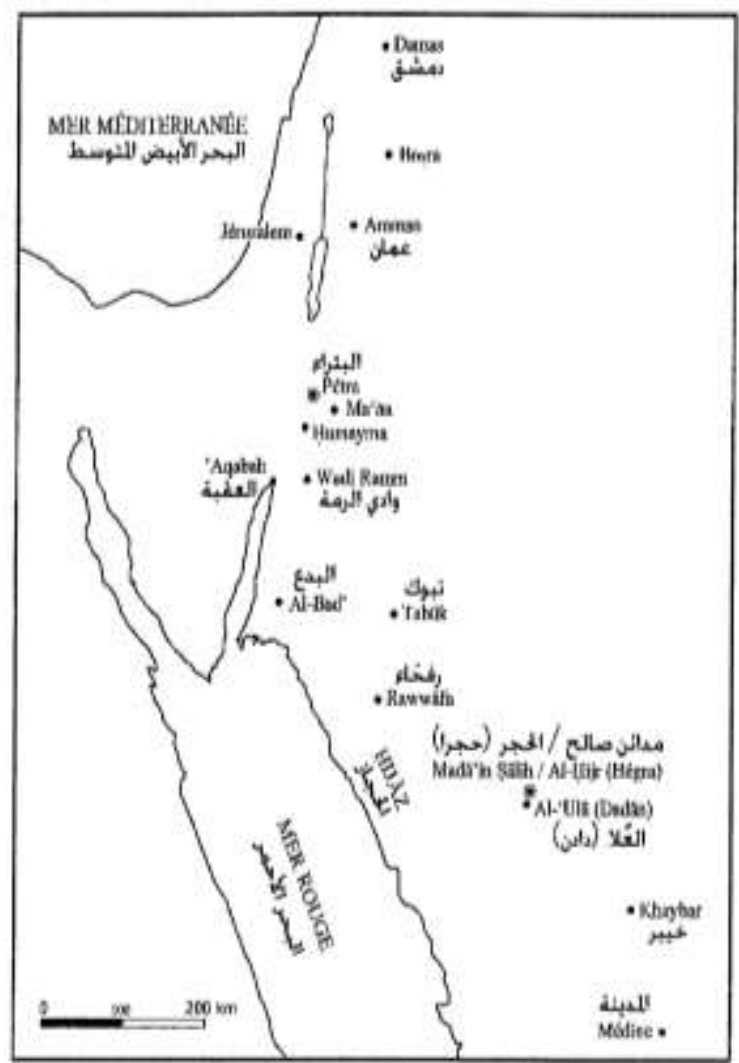

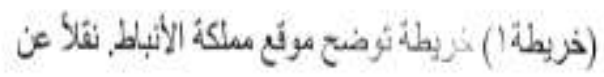

NEHME, L., Mission Archc ologicu de Madain

Salih(Arabie Saoudite): Recherches thene' es2001 a'2003 dans L'ancienne Hijre des Nabate' ens, (prnted in

Sngapore, 20061., ,42.

2 Hommand, c,ph op .cit,p,89. ' غرابية : المرجع السابق، ص00. 


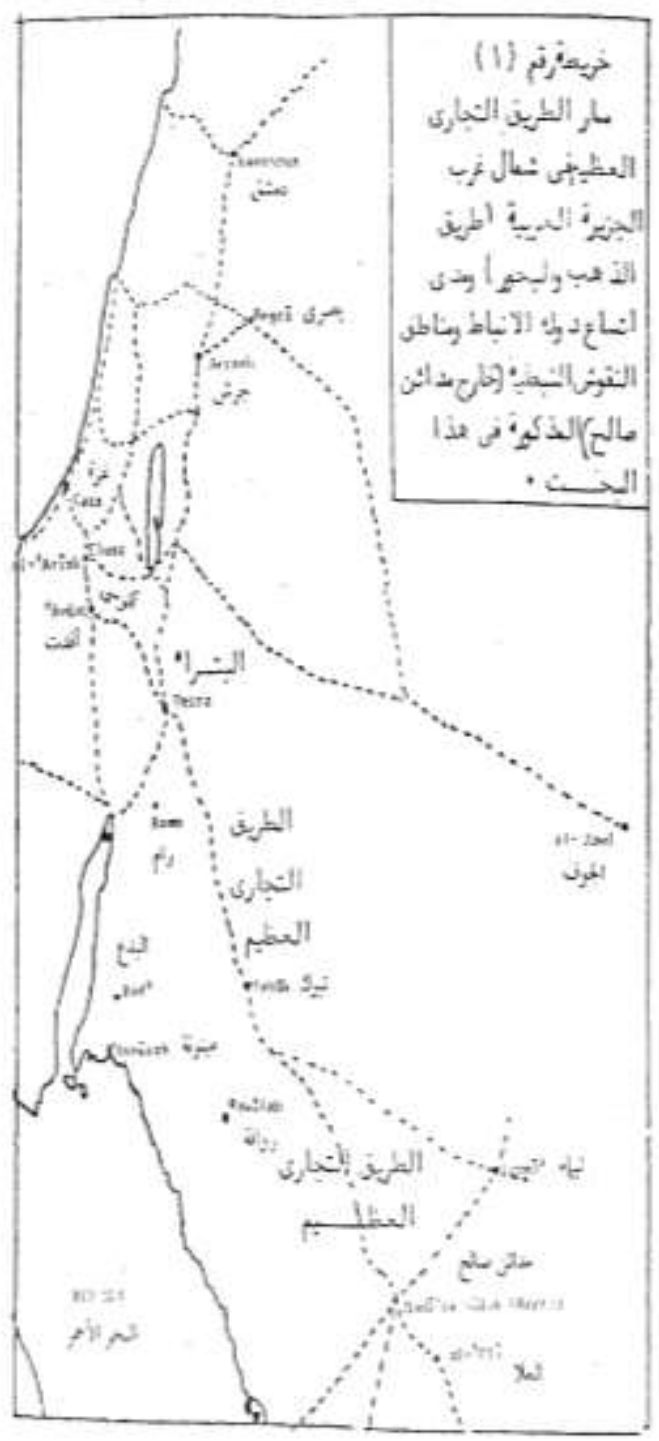

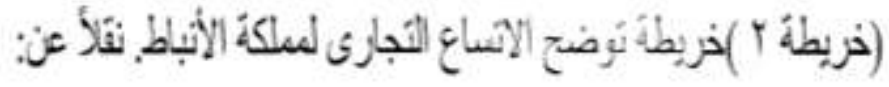

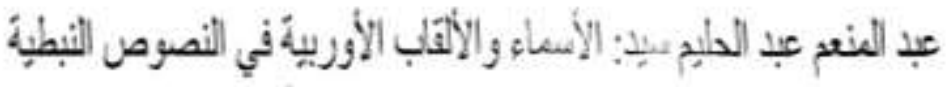

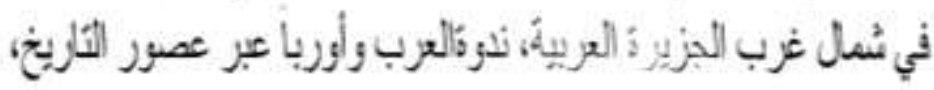 إقاهر}


المعبود ذو الثري ودوره في الديانة النبطية د.عحم دسوقي حسن عبد العزيز
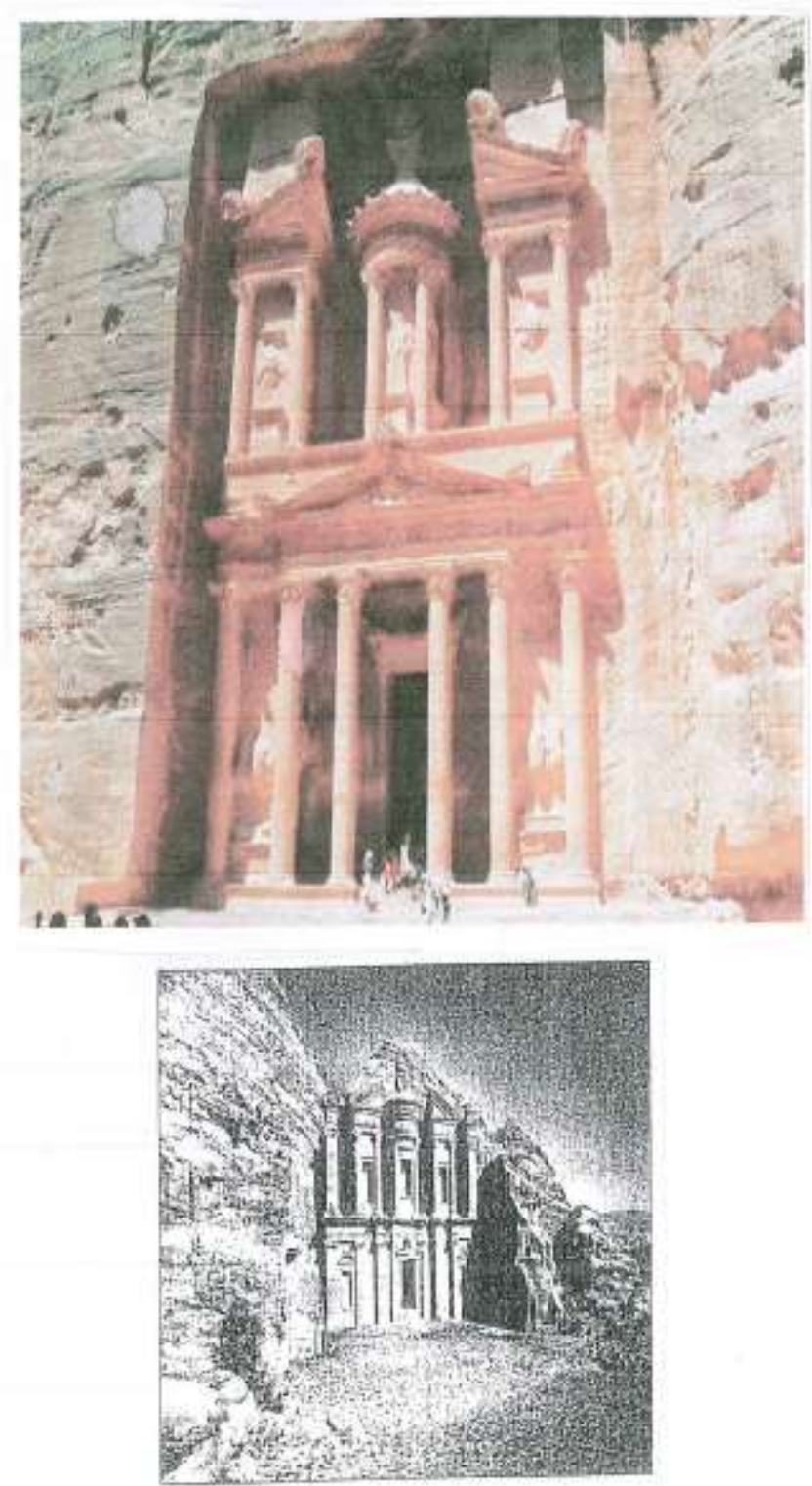

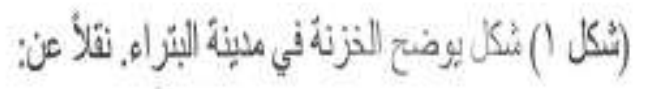

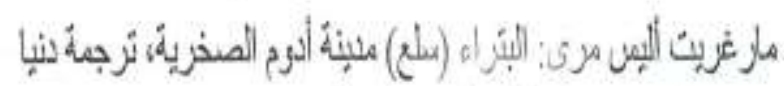

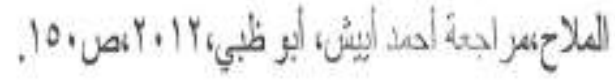


مجلة كلية التربية ـ جامعة الإسكندرية المجلد السادس والعشرون (العدد الخامس أ) لسنة 17 ـ ب

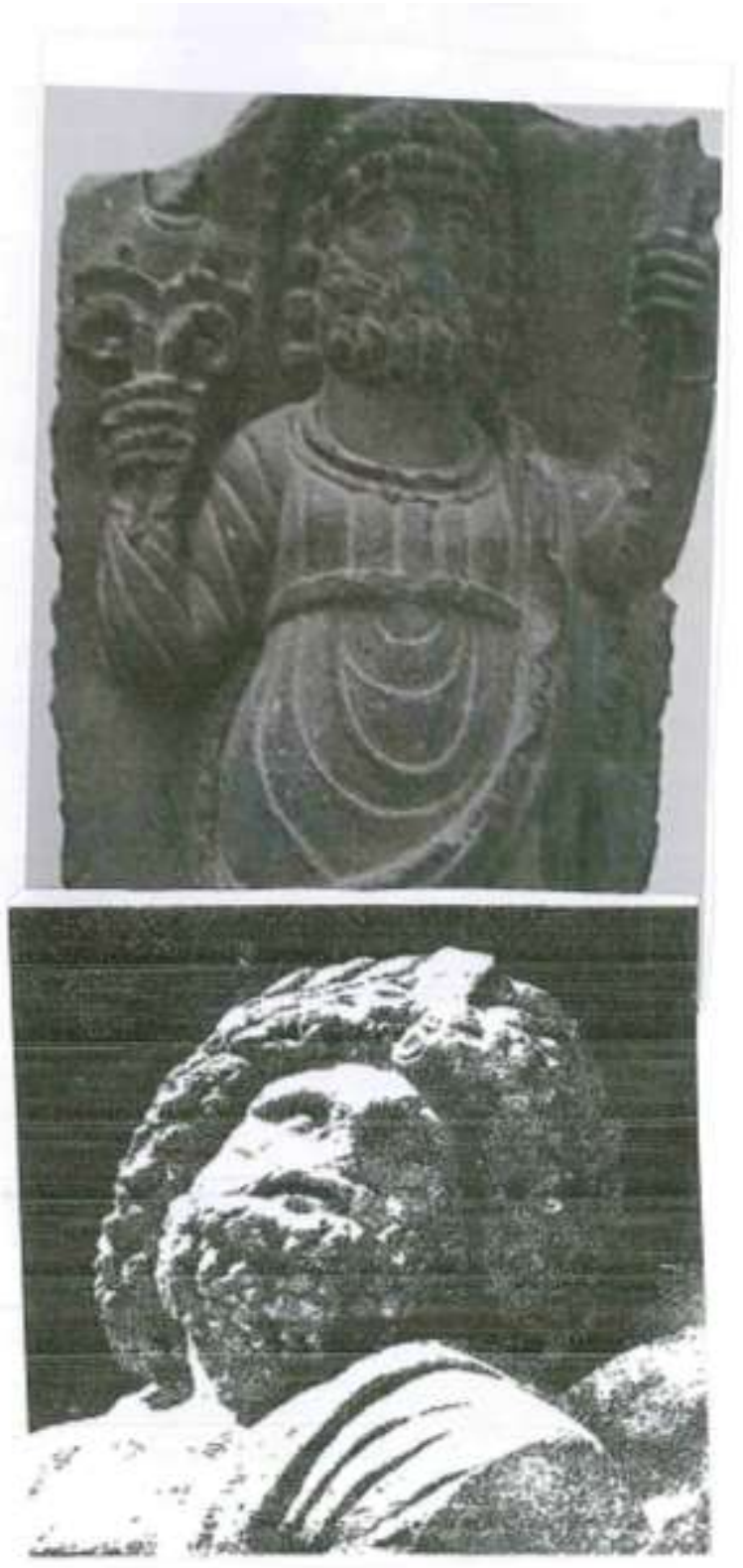

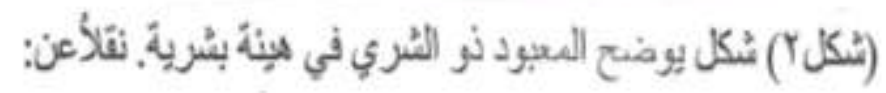

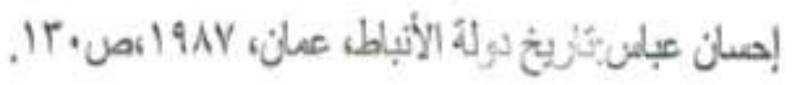


المبود ذو الثري ودوره في الديانة النبطية د.محم دسوقي حسن عبد العزيز
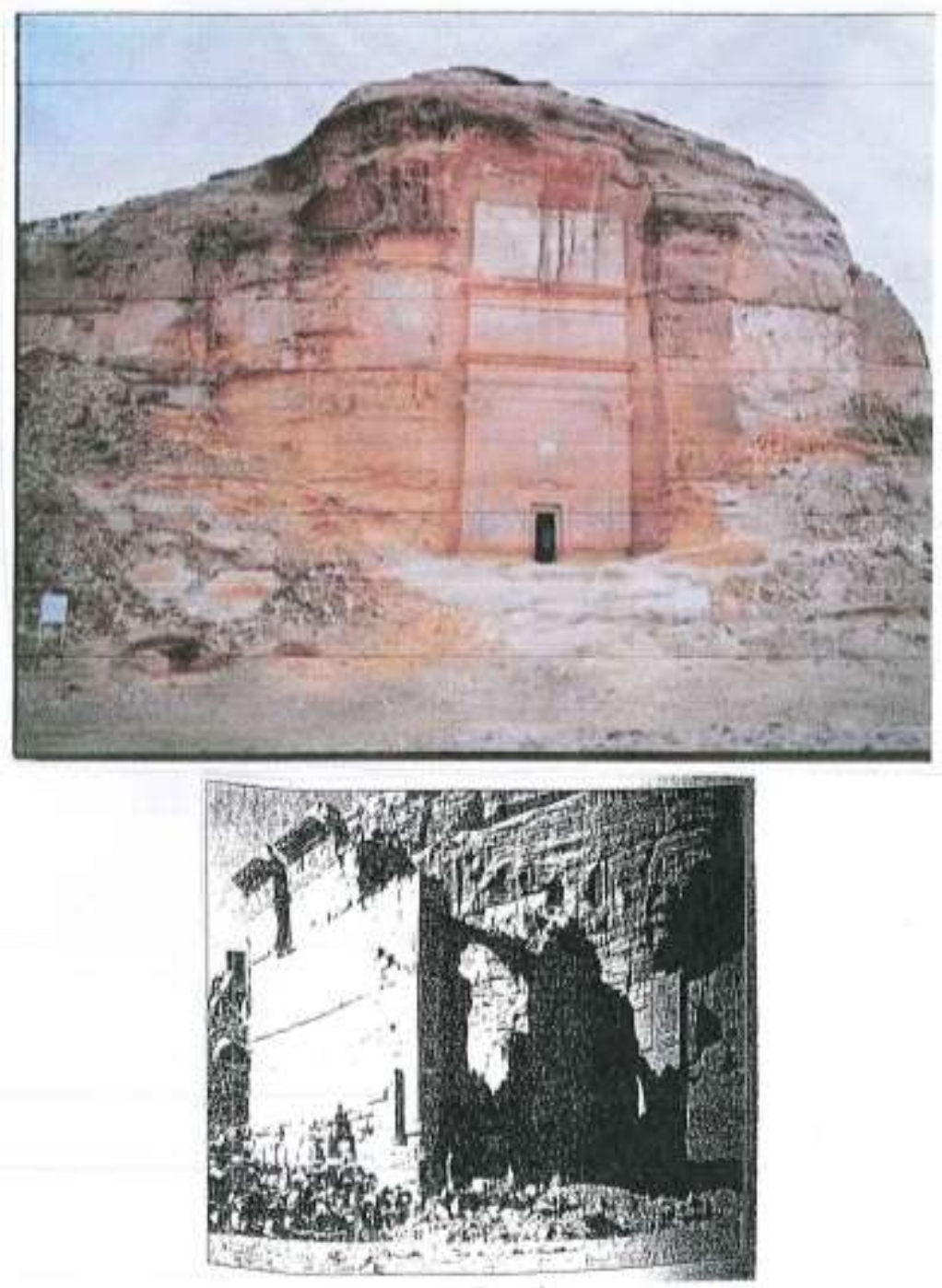

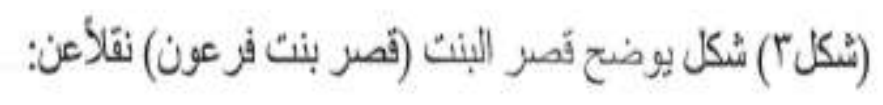

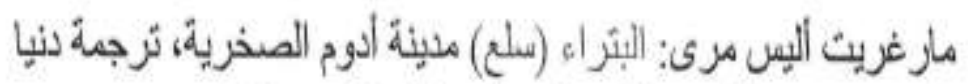

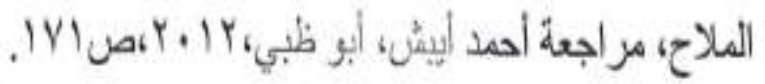


المجلد السادس والعشرون (العدد الخامس أ) لسنة 17 ـ

مجلة كلية التربية ـ جامعة الإسكندرية 